
.

\title{
Functional Characterization of Zebrafish Cytochrome P450 1 Family Proteins Expressed in Yeast
}

(1)

John J. Stegeman ${ }^{1}$, Lars Behrendt ${ }^{1 a}$, Bruce R. Woodin ${ }^{1}$, Akira Kubota ${ }^{1 b}$, Benjamin Lemaire $^{1 \mathrm{c}}$, Denis Pompon ${ }^{2,3,4}$, Jared V. Goldstone ${ }^{1}$ and Philippe Urban ${ }^{2,3,4}$

${ }^{1}$ Biology Department, Woods Hole Oceanographic Institution, Woods Hole, MA USA

${ }^{2}$ Laboratoire d'Ingenierie des Systèmes Biologiques et des Procédés, CNRS UMR 5504, Campus INSA, 135 Avenue de Rangueil, F-31400 Toulouse, France

3Université de Toulouse; INSA, UPS, INP; LISBP, 135 Avenue de Rangueil, F-31077 Toulouse, France

${ }^{4}$ INRA, UMR792 Ingénierie des Systèmes Biologiques et des Procédés, F-31400 Toulouse, France

${ }^{a}$ Current address: Department of Civil Engineering, Massachusetts institute of Technology, Cambridge MA, USA

${ }^{\mathrm{b}}$ Current address: Diagnostic Center for Animal Health and Food Safety, Obihiro University of Agriculture and Veterinary Medicine, Obihiro, Japan

c Current address: Institut des Sciences de la Vie, Université Catholique de Louvain, Louvainla-Neuve, Belgium

Number of tables - 5

Number of figures -8

Words in Abstract - 247

Corresponding author:

John Stegeman

Biology Department,

Redfield 3-42, MS \#32

Woods Hole Oceanographic Institution

Woods Hole MA 02543

jstegeman@whoi.edu 


\section{Abbreviations}

AhR, aryl hydrocarbon receptor

$\mathrm{BaP}$ or $\mathrm{BP}$, benzo[a]pyrene

BR, 7-benzoxyresorufin

BROD, 7- benzoxyresorufin O-debenzylation

CYP or P450, cytochrome P450

DMF, N,N-dimethylformamide

DTT, dithiothreitol

EFC, 7-ethoxy-4-trifluoromethyl-coumarin

EFEE, 7-ethoxyfluorescein ethylester

ER, 7-ethoxyresorufin

EROD, 7-ethoxyresorufin O-deethylation

LN2, liquid nitrogen

MBC, 7-methoxy-4-bromomethyl-coumarin

MD, molecular dynamics

MFC, 7-methoxy-4-trifluoromethyl-coumarin

MMC, 7-methoxy-4-methyl-coumarin

MOC, 7-methoxy-coumarin

$\mathrm{MR}$, 7-methoxyresorufin

MROD, 7-methoxyresorufin O-demethylation

MS, mass spectra

NAMD, nanoscale molecular dynamics

$\mathrm{PAH}$, polycyclic aromatic hydrocarbon

POR, NADPH-cytochrome P450 reductase

PR, 7-pentoxyresorufin

PROD, 7-pentoxyresorufin O-depentylation

TEDG buffer, Tris-HCl 50 mM, EDTA 1 mM, Glycerol 20\%, DTT 1 mM, pH 7.4

TEG buffer, Tris-HCl 50 mM, EDTA 1 mM, Glycerol 20\%, pH 7.4

TES50 buffer, Tris-HCl 50 mM, EDTA 1mM, Sorbitol $0.6 \mathrm{M} \mathrm{pH} 7.4$

Tetrol, 7,8,9,10-tetrahydrotetrol-benzo[a]pyrene

VTFM, variable target function method

9,10-diol, 9,10-dihydrodiol-benzo[a]pyrene

7,8-diol, 7,8-dihydrodiol-benzo[a]pyrene

9-OH, 9-hydroxy-benzo[a]pyrene

3-OH, 3-hydroxy-benzo[a]pyrene

$6 ß-\mathrm{OH}, 6 \mathrm{~b}-\mathrm{hyd}$ roxy-testosterone 


\section{Abstract}

Background: Zebrafish express five cytochrome P450 1 genes: CYP1A, CYP1B1, CYP1C1,

3 CYP1C2, inducible by aryl hydrocarbon receptor agonists, and CYP1D1, a constitutively

4 expressed CYP1A-like gene. We examined substrate selectivity of CYP1s expressed in yeast.

5 Methods: CYP1s were expressed in W(R) yeast, engineered to over-express P450

6 reductase, via pYES/DEST52 and via pYeDP60. Microsomal fractions from transformed yeast

7 were examined for activity with fluorogenic substrates, benzo[a]pyrene and testosterone.

8 Modeling and docking approaches were used to further evaluate sites of oxidation on

9 benzo[a]pyrene and testosterone.

10 Results: CYP1s expressed in yeast dealkylated ethoxy-, methoxy-, pentoxy- and benzoxy-

11 resorufin (EROD, MROD, PROD, BROD). CYP1A and CYP1C2 had the highest rates of EROD

12 activity, while PROD and BROD activities were low for all five CYP1s. The relative rates of

13 resorufin dealkylation by CYP1C1, CYP1C2 and CYP1D1 expressed via pYeDP60 were highly

14 similar to relative rates obtained with pYES/DEST52-expressed enzymes. CYP1C1 and

15 CYP1C2 dealkylated substituted coumarins and ethoxy-fluorescein-ethylester, while CYP1D1

16 did not. The CYP1Cs and CYP1D1 co-expressed with epoxide hydrolase oxidized BaP with

17 different rates and product profiles, and all three produced BaP-7,8,9,10-tetrol. The CYP1Cs but

18 not CYP1D1 metabolized testosterone to 6ß-OH-testosterone. However, CYP1D1 formed an

19 unidentified testosterone metabolite better than the CYP1Cs. Testosterone and BaP docked to

20 CYP homology models with poses consistent with differing product profiles.

21 Conclusions: Yeast-expressed zebrafish CYP1s will be useful in determining further

22 functionality with endogenous and xenobiotic compounds.

23 General Significance: Determining the roles of zebrafish CYP1s in physiology and

24 toxicology depends on knowing the substrate selectivity of these enzymes. 


\section{Introduction}

Enzymes in the vertebrate cytochrome P450 1 (CYP1) family metabolize many xenobiotics, including polycyclic aromatic hydrocarbons (PAH), natural products, and drugs. These metabolic activities have implications for environmental chemical effects in humans and wildlife, including carcinogenesis and other health outcomes [1-4], and for drug therapy in humans [5-8]. CYP1 enzymes also metabolize endogenous regulatory molecules, including steroids and arachidonic acid [2, 9-13]. Mammals express three CYP1 genes in two subfamilies, CYP1A (genes CYP1A1 and CYP1A2) and CYP1B (gene CYP1B1), all three of which are inducible by aryl hydrocarbon receptor (AHR) agonists [14]. Other vertebrates (fish, amphibians, birds) have four CYP1 subfamilies, CYP1A and CYP1B, as well as the more recently discovered CYP1C and CYP1D [15-20]. Teleost fish such as zebrafish typically have five CYP1 genes, CYP1A, CYP1B1, CYP1C1, CYP1C2 and CYP1D1 [16, 17]. Functional properties of the mammalian CYP1s are rather well known [14], but catalytic functions of the non-mammalian CYP1s by comparison remain poorly characterized.

The zebrafish is a major vertebrate model, yielding insights into mechanisms in normal developmental processes as well as in environmental toxicology and chemically induced diseases [21]. Zebrafish increasingly are used also in drug discovery and toxicity screening [22, 23]. Knowledge of the regulation and catalytic functions of the full suite of CYP1s (and indeed all CYPs) in zebrafish is important to strengthen inference from toxicological and pharmacological studies with this model. In teleost fish, four of the five CYP1 genes, i.e., CYP1A, CYP1B1, CYP1C1 and CYP1C2, are inducible by AHR agonists such as 3,3',4,4',5-pentachlorobiphenyl (PCB126) and benzo[a]pyrene (BaP) [24, 25], although with differing degrees of responsiveness that change over development [24]. Notably, CYP1C2 transcript inducibility diminishes

4 substantially after hatching, and it effectively is not inducible in adult liver [24, 26]. In contrast to

25 the other CYP1 genes, zebrafish CYP1D1 has not been found to be inducible by AhR agonists, 26 in adult or developmental stages [17]. CYP1D1 has a gene structure identical to that of CYP1A, 
1 but with a single dioxin response element in the $10 \mathrm{~kb}$ promoter region, and it appears to be

2 constitutively regulated. There also are pronounced tissue and developmental differences in

3 basal expression of the five CYP1s. For example, in adult zebrafish brain, CYP1D1 is relatively

4 more highly expressed than the other CYP1 genes [17].

5 Differences in tissue distribution, basal expression levels, and inducibility by AhR agonists

6 suggest that the five zebrafish CYP1s play different roles in vivo, which could as well involve

7 differences in substrate selectivity and catalytic efficiency of these proteins. Enzyme functions of

8 the CYP1As have been studied in several teleost species, including zebrafish (e.g.,[27]),yet the

9 substrate selectivity of the multiple CYP1s that occur in teleost species, including zebrafish, still

10 are poorly known. Here we report on catalytic functions of recombinant zebrafish CYP1

11 enzymes expressed in yeast, with a suite of fluorogenic substrates as well as with a model PAH

12 (BaP) and a model steroid (testosterone). The catalytic functions of the lesser-known CYP1s in

13 fish, the CYP1Cs and CYP1D1, in particular need attention, and we emphasize these enzymes.

14 Activities of the zebrafish CYP1s expressed in E. coli have been examined with a variety of

15 substrates like those we use here, and a different steroid substrate, $17 ß$-estradiol [28, 29]. The

16 results provide a foundation for further studies of CYP1s in the zebrafish model.

\section{2. Materials and Methods}

19 2.1. Chemicals

$20 \mathrm{NADPH}$, benzo[a]pyrene and testosterone were purchased from Sigma-Aldrich (St. Louis,

21 MO). The substituted resorufin substrates, 7-ethoxyresorufin, 7-methoxyresorufin, and 7-

22 pentoxyresorufin and 7-benzyloxyresorufin were from Sigma-Aldrich or from Molecular Probes

23 (Eugene, OR). The substrates 7-ethoxyfluorescein-ethylester (EFEE); 7-methoxy-coumarin; 7-

24 methoxy-4-methyl-coumarin; 7-methoxy-4-bromomethyl-coumarin; 7-methoxy-4-trifluoromethyl-

25 coumarin; and 7-ethoxy-4-trifluoromethyl-coumarin all were from Molecular Probes. Substrate

26 structures are shown in Figure 1. Other chemicals were from Fisher Scientific or Sigma-Aldrich. 


\subsection{Heterologous Expression}

The open reading frames of zebrafish CYP1s were amplified by PCR (using primers shown

in Supplemental Table 1), gel-purified using Nucleospin columns, and ligated into an entry vector, either pENTR/D/TOPO ${ }^{\circledR}$ (Invitrogen) or PCRScript (Stratagene), according to instructions.

CYP1s were expressed in the Saccharomyces cerevisiae W(R) strain (MATa; ade2-1; his311,15; leu2-3, 112; trp1-1; ura3-1; canR; cyr+), engineered to over-express the yeast microsomal NADPH-cytochrome P450 reductase (POR) [30]. In W(R) yeast transformed with CYP genes, POR activity has been found consistently to be at about 2,200 $\pm 200 \mathrm{nmol}$ cyt c reduced $/ \mathrm{min} / \mathrm{mg}$ of microsomal protein with cells cultivated in synthetic medium, and 3,200 \pm $200 \mathrm{nmol}$ cyt c reduced / $\mathrm{min} / \mathrm{mg}$ of microsomal protein from cells cultivated in rich medium. In the current work, $W(R)$ cells were cultivated in a rich medium.

Two approaches were taken using different expression vectors. In the first procedure, CYP1s were transferred from the entry vector $\mathrm{pENTR/D/TOPO} \mathrm{to} \mathrm{the} \mathrm{destination} \mathrm{vector}$ pYES/DEST52/V5-His using the TOPO Cloning Kit (Invitrogen), as per the kit protocol. A pYES/DEST52 plasmid carrying the Arabidopsis $\beta$-glucuronidase (gus) gene was used as a positive control for transformation and a negative control for CYP heterologous expression. In the second procedure, CYP1s were excised from the PCRScript entry vector and then ligated into the yeast expression vector pYeDP60 by standard ligation protocols, and an empty vector was used to prepare control yeast. Plasmids for yeast expression were purified from E. coli cultures grown overnight, and were used to transform competent yeast. Yeast cells were made competent using the S.c. EasyComp ${ }^{\mathrm{TM}}$ transformation kit according to the manufacturer's instructions (Invitrogen), or by using the standard lithium acetate procedure [31].

Single pYES/DEST52-transformed yeast colonies were picked from selective plates and used to inoculate $30 \mathrm{~mL}$ of SGAI medium [32]. Cultures in SGAI were grown overnight at $28^{\circ} \mathrm{C}$ with shaking at $130 \mathrm{rpm}$, then $10 \mathrm{~mL}$ was transferred to a 2-liter flask containing $500 \mathrm{~mL}$ of 
1 YPGE media [32]. YPGE cultures were grown overnight as above. Yeast cells were induced by

2 the addition of $2 \%$ galactose and incubated for various periods of time up to $18 \mathrm{hrs}$ at $28^{\circ}-30^{\circ} \mathrm{C}$

3 with shaking at 130 or $140 \mathrm{rpm}$. Cells were harvested by centrifugation, washed with TES50

4 buffer (50 mM Tris-HCl, 1 mM EDTA, 0.6 M sorbitol; $\mathrm{pH}$ 7.4) and cell pellets were used in whole

5 cell assays or frozen in liquid nitrogen (LN2) and stored at $-80^{\circ} \mathrm{C}$ for preparation of microsomal

6 fractions used in assay of catalytic activities.

7 Alternatively, pYEDP60 yeast colonies picked from selective plates were used to inoculate

$850 \mathrm{~mL}$ of SGAI medium, the cultures were grown overnight at $28^{\circ} \mathrm{C}$ with shaking at $160 \mathrm{rpm}$,

9 then transferred to a 1-liter flask containing $250 \mathrm{~mL}$ of YPGE media. The YPGE culture was

10 grown for $48 \mathrm{hrs}$ at $28^{\circ} \mathrm{C}$ with shaking at $140 \mathrm{rpm}$. Yeast cells were then induced by the addition

11 of $2 \%$ galactose for $12 \mathrm{hrs}$ at $28^{\circ} \mathrm{C}$ with shaking at $140 \mathrm{rpm}$. Cells were harvested by

12 centrifugation, washed with TES buffer (50 mM Tris-HCl, 1 mM EDTA, $0.6 \mathrm{M}$ sorbitol; $\mathrm{pH} 7.4$ )

13 and immediately processed for microsome preparation.

\section{2.3. Microsomal fraction preparation:}

15 Yeast cells from the first procedure (pYES/DEST52) were suspended in vacuum degassed

16 TES 50 buffer containing $1.0 \mathrm{mM}$ dithiothreitol (DTT) and protease inhibitor cocktail (1X)

17 (Sigma) and mechanically disrupted using the BeadBeater (BioSpec Products, Inc., Bartlesville,

18 OK). A $25 \mathrm{~mL}$ chamber containing glass beads $(0.5 \mathrm{~mm}$ diameter, amounting to $1 / 2$ the total

19 volume) and the yeast cell slurry was cooled with an ice water/methanol (20\%) cooling jacket.

20 Air remaining in the chamber was displaced by adding degassed TES 50 buffer. The cells were

21 disrupted by twenty 5-s BeadBeater cycles with 45-s resting (cooling) periods between cycles.

22 This method of disruption has been shown to be effective at maintaining the sample

23 temperature below $8^{\circ} \mathrm{C}$ during disruption and results in greater than $90 \%$ lysis of yeast cells.

24 All subsequent steps were carried out at $4^{\circ} \mathrm{C}$. Cell lysate was decanted and the beads

25 remaining in the chamber were washed once with $2 \mathrm{~mL}$ of degassed buffer, which was then

26 added to the cell lysate. The cell lysate was then centrifuged with conditions used before [33] to 
1 collect the microsomal fraction. The resulting microsomal pellet was resuspended in 1 to $2 \mathrm{~mL}$

2 of TEDG buffer (50 mM Tris-HCl, 1 mM EDTA, 20\% glycerol by volume, $1 \mathrm{mM}$ DTT, pH 7.4) by

3 gentle hand homogenization using a Potter-Elvehjem homogenizer and microsomal

4 suspensions were stored in LN2. An aliquot of suspension was taken for microsomal protein

5 determination using the BCA protein assay (Pierce) with BSA as the standard [34].

6 Yeast cells from the second procedure (with the pYeDP60 vector) were suspended in a

7 minimal volume of TES buffer (usually 1.5-2.0 ml) and hand-broken using glass microbeads

$8\left(0.4-0.5-\mathrm{mm}\right.$ diameter) at $4^{\circ} \mathrm{C}$. All subsequent steps were carried out at $4^{\circ} \mathrm{C}$. Microsomal

9 fractions were prepared from disrupted yeast cells using a glycerol- $\mathrm{NaCl}$ precipitation procedure

10 as previously described [32]. The resulting microsomal pellet was resuspended in $1 \mathrm{~mL}$ of TEG

11 buffer (50 mM Tris-HCl, 1 mM EDTA, 20\% glycerol by volume, $\mathrm{pH} 7.4$ ) as above. An aliquot of

12 the suspension was taken for microsomal protein determination as above, and for CO-reduced

13 spectral measurement of total P450.

14 Microsomal proteins from pYES/DEST52 yeast cells expressing the CYP1s were resolved

15 electrophoretically and blots probed with antibody to the V5 epitope. As a surrogate for the

16 amounts of P450 expressed, the amounts of $\mathrm{V} 5$ tag were determined by Image $\mathrm{J}$ analysis of the

17 stain density of bands in the immunoblot. In addition, microsomes from pYES/DEST52 yeast

18 expressing CYP1A were stained with antibodies to CYP1A.

19 2.4. Assay of Catalytic Activities:

20 Activities with substituted resorufin substrates (ethoxy-, methoxy-, pentoxy- and

21 benzyloxyresorufin) were measured in yeast microsomal fractions, and also in intact yeast cells,

22 with endogenous NADPH. For assay of intact cells, freshly prepared yeast cell pellets were

23 diluted to $200 \mathrm{mg} / \mathrm{ml}$ in assay buffer (50 mM Tris, $0.1 \mathrm{M} \mathrm{NaCl}, \mathrm{pH} 7.8$ ). Control samples were

24 boiled yeast and yeast expressing Arabidopsis $\beta$-glucuronidase (gus). Reactions were initiated

25 by mixing 1 volume of yeast suspension with 1 volume of $8 \mu \mathrm{M}$ resorufin substrate in assay

26 buffer ( $4 \mu \mathrm{M}$ final concentration of substrate), and incubated at $30^{\circ} \mathrm{C}$. Duplicate $150 \mu \mathrm{l}$ aliquots 
1 were taken at $0,5,10,15$ and 30 min after mixing, and placed immediately on ice to stop the

2 reaction. Aliquots of reaction mixtures were centrifuged to remove yeast cells and $100 \mu \mathrm{l}$ of

3 supernatant fluid was transferred to a 96 well plate and fluorescence was measured and

4 compared to resorufin standards, using a fluorescence plate reader as described previously [35,

5 36]. Activities in pmol $\mathrm{min}^{-1} \mathrm{mg}^{-1}$ whole yeast protein were determined from the linear portion of

6 the resorufin production time course.

7 Activities of microsomal fractions prepared from transformed yeast cultures with the

8 substituted resorufin substrates were assessed kinetically using a fluorescence plate reader as

9 above, at $30^{\circ} \mathrm{C}$, in a buffer of $50 \mathrm{mM}$ Tris, $0.1 \mathrm{M} \mathrm{NaCl}, \mathrm{pH}$ 7.8. Activities obtained with CYPs in

10 yeast microsomal preparations were determined from the linear portion of the resorufin

11 production time course, in pmol $\mathrm{min}^{-1} \mathrm{mg}^{-1}$. Activity with substituted resorufins also was

12 measured with a spectrofluorometer, using an excitation wavelength of $530 \mathrm{~nm}$ and an emission

13 wavelength of $586 \mathrm{~nm}$. NADPH concentrations were $120 \mu \mathrm{M}$ and substrate was saturating.

14 Stock solutions were prepared in methanol, and the final concentration of methanol in

15 incubation mixtures was $0.2-0.3 \%$.

16 Activities with the substrates 7-methoxy-, 7-methoxy-4-methyl-, and 7-methoxy-4-

17 bromomethyl-coumarin were measured fluorometrically using excitation and emission

18 wavelengths at $380 \mathrm{~nm}$ and $460 \mathrm{~nm}$, respectively, and with 7-methoxy- and 7-ethoxy-4-

19 trifluoromethyl-coumarin activities were determined with excitation and emission wavelengths

20 set at $385 \mathrm{~nm}$ and $502 \mathrm{~nm}$, respectively. For these assays, reactions were in $1 \mathrm{ml}$ of $50 \mathrm{mM}$

21 Tris- $\mathrm{HCl}$ buffer (pH 7.4) containing 1 mM EDTA, substrate at $2 \mu \mathrm{M}$ (saturating), and $100 \mu \mathrm{g}$ of

22 yeast microsomal protein; reactions were initiated by adding NADPH to achieve $150 \mu$ M. Stock

23 solutions of coumarins were prepared in methanol, except for 7-methoxy-4-bromomethyl-

24 coumarin which was prepared in N,N-dimethylformamide (DMF). The final concentration of

$25 \mathrm{MeOH}$ or DMF in incubation mixtures was $0.2 \%$.

26 Ethoxyfluorescein ethyl ester O-deethylase activities were measured fluorometrically using 
1 excitation and emission wavelengths set at $479 \mathrm{~nm}$ and $560 \mathrm{~nm}$, respectively. Reactions were

2 carried out in $1 \mathrm{ml}$ of $50 \mathrm{mM}$ Tris-HCl buffer ( $\mathrm{pH}$ 7.4) containing $1 \mathrm{mM}$ EDTA, NADPH $120 \mu \mathrm{M}$,

3 EFEE $1 \mu \mathrm{M}$ (saturating), and $150 \mu \mathrm{g}$ of yeast microsomal proteins. The stock solution of EFEE

4 was prepared in methanol, with a final concentration of $0.1 \%$ in incubation mixtures.

5 Saturation of the different fluorogenic substrates was determined by the usual kinetic

6 method that consists of two parallel incubations, one with the presumed saturating

7 concentration of the substrate, the other with half this concentration. The calculated reaction

8 rates for the two incubations are compared, and if they are of similar value within experimental

9 error, the concentration is said to be saturating.

10 Rates of benzo[a]pyrene oxidation were determined using a radiometric assay with ${ }^{14} \mathrm{C}$ -

$11 \mathrm{BaP}$, modified from a method described previously [37]. Replicate $100 \mu \mathrm{l}$ reaction mixtures

12 contained CYP1C1 or CYP1C2 yeast microsomal protein (1-2 mg/ml final concentration),

13 uniformly labelled ${ }^{14} \mathrm{C}-\mathrm{BaP} 70 \mu \mathrm{M}$ final concentration in $50 \mathrm{mM}$ Tris buffer, $\mathrm{pH}$ 7.4. Reactions

14 were initiated with addition of $\mathrm{NADPH}\left(0.25 \mathrm{mM}\right.$, final concentration), and incubated at $28^{\circ} \mathrm{C}$.

15 Reactions were stopped at various intervals with $0.15 \mathrm{M} \mathrm{KOH}$ in DMSO on ice, extracted with

16 hexane, and aliquots of the aqueous phase added to scintillation vials prefilled with $3 \mathrm{~mL}$

17 Scintaverse $+10 \mu \mathrm{L} 0.6 \mathrm{~N} \mathrm{HCl}$, and counted with a Beckman LS 6500 scintillation counter.

18 Blank reactions without NADPH were included as controls.

19 Reaction mixtures for generation of metabolites of benzo[a]pyrene and testosterone

20 contained $50 \mathrm{mM}$ Tris-HCl buffer, 1 mM EDTA, pH 7.4, recombinant zebrafish CYP in 250 or

$21300 \mathrm{mg}$ total yeast microsomal protein, yeast-expressed human microsomal epoxide hydrolase

22 in $200 \mathrm{mg}$ total microsomal protein, $0.2 \mathrm{mM} \mathrm{NADPH}$, in a final volume of $0.33 \mathrm{ml}$. Incubations

23 were at $28^{\circ} \mathrm{C}$. Benzo[a]pyrene was added at a final concentration of $12 \mu \mathrm{M}$, from a stock

24 solution in DMF; the final concentration in DMF of the incubation mixtures was $1 \%$. For

25 testosterone metabolism assays, epoxide hydrolase was omitted and the substrate

26 concentration was $120 \mu \mathrm{M}$ from a stock solution in methanol. The final concentration in 
1 methanol of the incubation mixtures was $0.1 \%$. Reactions were stopped at different intervals by

2 adding $5 \mu \mathrm{L}$ trifluoracetic acid in water (1:1 vol.) and one volume of acetonitrile, and the mixture

3 was centrifuged at $10,000 \mathrm{rpm}$ for $10 \mathrm{~min}$ to remove membranes and precipitated proteins. An

4 aliquot of the supernatant $(10-30 \mu \mathrm{L})$ was analyzed by HPLC separation, as below.

5 2.5. Reverse phase high-throughput HPLC analyses

$6 \quad$ The BaP and testosterone metabolites were separated and analyzed on an Alliance

7 HT2795 HPLC Waters module connected to both a Waters 2475 fluorescence detector and a

8 Micromass ZQ mass spectrometer with a Spheri-5 RP18 $5 \mu \mathrm{m}$ Brownlee column (4.6x100-

$9 \mathrm{~mm}$ ). The column was heated at $40^{\circ} \mathrm{C}$ for better peak resolution. Metabolites were separated

10 using a gradient starting at 90:10 (water:acetonitrile) followed by a linear increase to 0:100 over

$1110 \mathrm{~min}$ and, then, by a plateau at $100 \% \mathrm{CH} 3 \mathrm{CN}$ for $2 \mathrm{~min}$, and return to initial conditions and

12 hold for $2 \mathrm{~min}$; $14 \mathrm{~min}$ of total run length. For identification of metabolites from BaP, the

13 fluorescence detection was set at $278 \mathrm{~nm}$ for excitation and $407 \mathrm{~nm}$ for emission, and

14 chromatographic quantitation was standardized with benzo[ghi]perylene as an internal

15 standard. Testosterone metabolites were identified and quantified by mass spectrometry with

16 electrospray positive ionization. Parameters of ionization were as follows: capillary voltage 3.4

$17 \mathrm{kV}$, cone voltage $20.0 \mathrm{~V}$, desolvation gas flow $550 \mathrm{~L} . \mathrm{h}-1$, desolvation temperature $350^{\circ} \mathrm{C}$, and

18 source temperature $120^{\circ} \mathrm{C}$. Continuous metabolite mass detection was using both full scan

19 spectra by scanning mass range 200-500 amu and a SIR channel (single ion response) set at

20 the precise $m / z$ corresponding to the protonated mass of hydroxytestosterone: $[M+H]^{+}=305.4$.

21 The detected $\mathrm{m} / \mathrm{z}$ corresponds to $\mathrm{M}+\mathrm{H}$ since positive electrospray mode is used. The amounts

22 of metabolite were quantified by measuring peak areas from the SIR data. Initial velocities

23 were determined by plotting the peak area vs. time for each metabolite after 5, 10, 15, and 20

24 min of incubation.

\section{$25 \quad$ 2.6. Homology Modeling and Docking}

26 Homology models of zebrafish CYP1C1, CYP1C2 and CYP1D1 were constructed using 
1 Modeller9v8 [38], based on the crystal structures of human CYP1A2 [39] and CYP1B1 [40].

2 The N-terminal membrane anchor regions of the fish CYP1A sequences were truncated to

3 match the sequence of the human structure. Initial CLUSTALX alignments were refined using

4 the salign_2d function of Modeller. Default parameters in Modeller were applied, excluding

5 water molecules and any ions that were part of any of the templates with the exception of the

6 heme and heme iron. Homology modeling was carried out by satisfaction of spatial restraints

7 using the automodel function of Modeller, with very thorough variable target function method

8 (VTFM), thorough molecular dynamics (MD), and two repeat cycles of minimization. One

9 hundred randomly seeded models were generated for each protein. Side chain positions were

10 optimized in a solvated model by molecular dynamics minimization and equilibration using

11 NAMD (NAnoscale Molecular Dynamics freeware) (v2.8) [41]. The P450 heme-cysteine bonds

12 were explicitly patched, and models were solvated in a cube of water to allow periodic

13 boundary condition, charge-neutralized, and minimized for 100 steps prior to relaxation for

142500 steps (5ps). Models and crystal structures were prepared for docking using

15 AutoDockTools (v1.5.4) [42], with the addition of polar hydrogens and the assignment of

16 Gasteiger charges. Ligand structure and charge minimization was performed with

17 semiempirical methods (PM6 Hamiltonian in Mopac2009 [43, 44]). Gasteiger-Marsili partial

18 charges were used in the final docking runs. High throughput docking was performed using

19 Autodock Vina (v1.1.1) [45]. Flexible ligands were docked into models with rigid protein

20 backbones and rigid side chains, performing 100 replicate dockings and retaining a broad

21 range of calculated energies $(6 \mathrm{kcal} / \mathrm{mol})$. 


\section{3. Results}

2 3.1. Activity of Five Zebrafish CYP1s expressed via pYES/DEST52

3 Initially, we examined expression of the five CYP1s in W(R) yeast via the pYES/DEST52/V5-

4 His vector. Immunoblot assay for the V5 tag in microsomal fractions of yeast induced with

5 galactose showed V5 tag expression in each case, confirming successful expression of the

6 CYPs (Figure 2). Examining the time-course of V5 tag levels, we determined that maximal

7 expression occurred between 12-18 hrs after addition of galactose (not shown). Immunoblotting

8 of microsomal fractions of CYP1A-transformed yeast with monoclonal antibody 1-12-3 that

9 recognizes zebrafish CYP1A confirmed the yeast expression of CYP1A (Supplemental Figure

10 1). Prior immunoblotting [17] had confirmed the expression of CYP1D1.

11 Although immunoblot assays for V5 tag or specific CYPs indicated expression of the target

12 proteins, we were unable to detect P450 spectrophotometrically in microsomal fractions of yeast

13 transformed with CYP1s via pYES/DEST52/V5-His. However, screening for enzyme activity in

14 intact cells showed that both EROD and MROD could be detected in yeast transformed with

15 CYP1s, but not in yeast transformed with Arabidopsis $\beta$-glucuronidase (not shown).

16 Following the demonstration of functional CYP in intact yeast cells, specific activities with the

17 four substituted resorufins were measured kinetically, at saturating substrate concentrations,

18 using microsomal fractions prepared from CYP1 transformed (pYES/DEST52) yeast strains.

19 Activity with one or more of the resorufin substrates was detected with microsomal fractions

20 from yeast transformed with the zebrafish CYP1s, but not with microsomes from control yeast

21 transformed with Arabidopsis $\beta$-glucuronidase, or with CYP1 yeast microsomes that were boiled

22 prior to assay. Microsomal recombinant CYP1A had the highest rates of EROD activity, and

23 MROD activity of CYP1A was approximately $2 / 3$ the rate of EROD at saturating concentrations

24 of substrate (Table 1 and Figure 3, left panel). The profile of CYP1B1 was different in that

25 MROD seemed to be greater than EROD. The CYP1C1 profile seemed to be similar to CYP1A,

26 while CYP1C2 yeast microsomes had EROD rates that were substantially greater than the 
1 MROD, which was less than $10 \%$ of the rates with 7-ER (Figure 3). With all five CYP1s, the

2 rates with 7-BR and 7-PR were less than those with 7-ER or 7-MR (Figure 3).

3 The immunoblot of V5 tag (Figure 2) indicated that there were differences in amounts of the

4 CYP1 proteins expressed, which would affect the values for activity per mg of yeast microsomal

5 protein. Determining the amounts of $\mathrm{V} 5$ tag on the immunoblots allowed us to normalize the

6 levels of catalytic activity to the amounts of protein expressed (Supplemental Table 2). While

7 this normalization did affect the absolute activities, the relative activities of a given enzyme with

8 the various substrates were unchanged (Supplemental Figure 3). Since the relative amounts of

9 yeast POR do not vary significantly from one microsomal preparation to another [30, 46-48],

10 differences in amounts of yeast POR in microsomal fractions here are not likely to contribute to

11 the observed differences in activity between the zebrafish CYP1s.

12 3.2. Activity of CYP1Cs and CYP1D1 expressed via pYeDP60

13 Next we focused on characterizing activity of the CYP1Cs and CYP1D1, with a broader set

14 of substrates, using yeast transformed via the pYeDP60 vector. As above, we initially tested

15 intact cells for activity with the substituted resorufins. Cells that had been transformed with an

16 empty vector had no activity, while cells transformed with CYP1C1, CYP1C2 and CYP1D1 via

17 pYeDP60 all showed activity with 7-ER, indicating expression of catalytically active enzyme

18 (data not shown). Subsequent analysis of microsomal preparations from yeast transformed with

19 CYP1C1, CYP1C2, or CYP1D1 showed again that all three enzymes acted on substituted

20 resorufins as substrates (Table 1 ). The CYP1Cs also acted on EFEE. All activities were

21 NADPH-dependent, as under identical conditions no product formation was observed with

$22 \mathrm{NADH}$ (not shown).

23 The rates of activity of microsomal preparations of yeast transformed with CYP1s via

24 pYeDP60 were greater than rates obtained with microsomes of yeast transformed with the

25 same CYPs via pYES/DEST52 (Table 1). However, the relative specific activities with the four

26 substituted resorufin substrates (normalized to EROD activity in each case) were highly similar 
1 for recombinant enzymes from yeast transformed via pYeDP60 and pYES/DEST52 (Figure 3).

2 This is evident also comparing the EROD to MROD ratios; for example, with CYP1C1 this ratio

3 was 1.3 with the pYES/DEST52-expressed enzyme and with the pYeDP60 expressed enzyme.

$4 \quad$ Spectrophotometric analysis of microsomal fractions prepared from yeast transformed with

5 CYP1C1 and CYP1C2 via pYeDP60 had CO-bound reduced absorbance at ca $450 \mathrm{~nm}$,

6 consistent with P450 (e.g., illustrated in Figure 4). Turnover numbers ( $\left.k_{\text {cat }}\right)$ for substrate

7 oxidation were calculated with CYP1Cs, using microsomal fractions that had quantifiable P450

8 levels (Table 2). The $k_{\text {cat }}$ for metabolism of the substituted resorufin substrates and EFEE (Table

9 2) indicate that the yeast expressed CYP1Cs are quite efficient catalysts for these activities. The

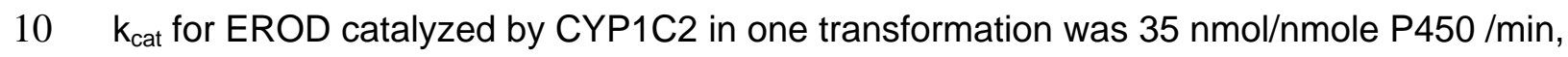

11 higher than that for human or rodent CYP1A1 expressed in the same yeast strain with the same

12 vector [49]. Although CYP1D1 showed catalytic activity with resorufins, the microsomal P450

13 content was very low and in most preparations was not detected, consistent with a lesser

14 expression of CYP1D1. The lower activity of yeast-expressed CYP1D1 was reflected also in a

15 higher $\mathrm{K}_{\mathrm{m}}$ with 7-ER (Table 2).

16 Given that we observed greater specific activities of the pYeDP60-expressed CYP1Cs and

17 CYP1D1 than those expressed via PYES/DEST52, we used these enzymes to assess the

18 activity with additional fluorogenic substrates. In addition to EFEE, we examined 7-methoxy-

19 coumarin, 7-methoxy-4-methyl-coumarin, 7-methoxy-4-bromomethyl-coumarin, 7-methoxy-4-

20 trifluoromethyl-coumarin, and 7-ethoxy-4-trifluoromethyl-coumarin (see Figure 1). Both CYP1C1

21 and CYP1C2 were active with all of these substrates. While the activity of pYeDP60-expressed

22 CYP1C2 with 7-ER seemed to exceed the activity of CYP1C1 the reverse appeared to be true

23 with some of the coumarin substrates, particularly MMC, MBC and MFC (Table 3). Although

24 CYP1D1 was weakly active with the resorufin substrates, it had no O-dealkylase activity with

25 any of the coumarins or with the EFEE. However, preliminary studies suggest it may be active in 26 hydroxylation of some of these coumarins (unpublished data). 


\subsection{Benzo[a]pyrene Oxidation}

Microsomes from the yeast transformed via pYeDP60 were used in radiometric assays to measure the overall activity of CYP1Cs and CYP1D1 with B[a]P. The rates of total B[a]P metabolism with this assay were $0.81 \mathrm{nmol} \mathrm{min}^{-1} \mathrm{nmol}^{-1}$ microsomal P450 for CYP1C1, and 2.26 nmol $\mathrm{min}^{-1} \mathrm{nmol}^{-1} \mathrm{P} 450$ for CYP1C2. CYP1D1 metabolism of BaP was not quantifiable with the radiometric assay. However, metabolites of $\mathrm{BaP}$ were generated in reactions together with human epoxide hydrolase for all three enzymes. Both CYP1C1 and CYP1C2 formed multiple metabolites of BaP (Figure 5), including the 9,10-dihydrodiol-BP, 7,8-dihydrodiol-BP, 3-hydroxyBP and 9-hydroxy-BP derivatives, and the 7,8,9,10-tetrol-BP. The tetrol metabolite observed with zebrafish CYP1s co-eluted with the authentic tetrol produced by human CYP1A1 in the presence of epoxide hydrolase, consistent with identity as the $7 \beta, 8 \alpha, 9 \alpha, 10 \beta$-tetrahydrotetrol derivative.

The ratio of CYP1C2 to CYP1C1 activity calculated from rates of formation of the sum of metabolites of BaP per nmol P450 was 2.40, close to the ratio of rates measured with the radiometric assay, 2.79. CYP1D1 yeast microsomes also formed 7,8,9,10-tetrol-BP and the 9hydroxy-BP and 3-hydroxy-BP metabolites, but the amounts formed were less than $0.2 \%$ of the amounts formed by CYP1C yeast microsomes. BaP-4,5-dihydrodiol and quinones were not examined in this analysis. Finally, BaP was shown to be a competitive inhibitor of EROD activity

for the zebrafish enzymes, with a $K_{\mathrm{i}}$ in the range of $100 \mathrm{nM}$ for both CYP1Cs and in the range of $10 \mu \mathrm{M}$ for CYP1D1. Thus, the affinity of BaP for CYP1D1 appears to be a hundred times lower than that for either of the CYP1Cs (Table 4).

\subsection{Testosterone Oxidation}

CYP1C1, CYP1C2 and CYP1D1 all were able to oxidize testosterone, forming three metabolites; one that was identified as $6 ß-\mathrm{OH}$-testosterone and two that were unidentified (M1 and $\mathrm{M} 2$ in Figure 6). The major metabolite was $6 ß-\mathrm{OH}$-testosterone, and was formed in greater amounts by CYP1C1 than CYP1C2 (Figure 6). CYP1D1 produced very little 6ß- 
1 hydroxytestosterone, less than $0.5 \%$ of the amount formed by CYP1C1. However, despite

2 being sluggish with testosterone overall, the hydroxylated metabolite M1 was formed by

3 CYP1D1 at nearly twice the rate of the CYP1Cs (per mg of microsomal protein) (Figure 6).

\section{$4 \quad$ 3.5. Homology Modeling and Docking}

5 An analysis of docked orientations of potential substrates BaP and testosterone suggest

6 likely sites of oxidation that support the in vitro data with the CYP1Cs and CYP1D1. Although in

7 this study we did not analyze BaP metabolism by zebrafish CYP1A or CYP1B1, others have

8 identified BaP metabolites formed by those enzymes (expressed in E. coli) [29] and we

9 therefore modeled those CYPs and docked BaP to them as well. BaP docked in a family of

10 productive orientations that was planar in CYP1A, CYP1B1, CYP1C1 and CYP1C2, but not in

11 CYP1D1 (Supplemental Figure 3). The top poses in CYP1A, CYP1B1, CYP1C1 and CYP1C2

12 were those with the benzo-ring of BaP oriented toward the heme iron (Figure 7). BaP docking in

13 CYP1D1 differed from the other CYP1s, with some poses that were out of the plane and not

14 likely productive. The top poses had the 3-carbon positioned toward the heme iron, rather than

15 the benzo-ring as in the other CYP1s (Figure 7). Relative energy calculations also show that

16 BaP docking to CYP1D1 was less favored than to the CYP1Cs by an average of $2.6 \mathrm{kcal} / \mathrm{mol}$

17 (Table 6), corresponding to a 100-fold higher calculated $K_{D}$ for CYP1D1.

18 Docking of testosterone to the CYP1Cs showed that the top productive poses have the A- and

19 B-rings positioned proximal to the heme iron, which would allow the 6-carbon to potentially be in

20 an oxidizable position (Figure 8). The docking of testosterone in CYP1D1 differed from the

21 CYP1cs, in that the orientations were more diverse (Supplemental Figure 4), and the top poses

22 showed the D-ring proximal to the heme. Docking of testosterone to the CYP1A and CYP1B1

23 models showed orientation similar to that in the CYP1Cs (Figure 8), allowing a prediction that

24 they would have similar product profiles. Testosterone affinity values were $2-3 \mathrm{kcal} / \mathrm{mol}$ lower

25 than for BaP, and both CYP1D1 and CYP1B1 were predicted to have relatively poor binding of 26 testosterone. 


\section{4. Discussion}

\subsection{Fluorogenic substrates}

Zebrafish have five CYP1 genes, CYP1A, CYP1B1, CYP1C1, CYP1C2 and CYP1D1. In

4 these studies we expressed all five CYP1s in W(R) yeast via pYES/DEST52, and also

5 expressed the CYP1Cs and CYP1D1 via pYeDP60. The yeast-expressed recombinant

6 enzymes were variously active with alkyl- or benzyl-substituted resorufin substrates commonly

7 used to characterize CYP1 enzymes. Among the five CYP1s expressed via pYES/DEST52, the

8 highest activity with ER was obtained with CYP1A, consistent with CYP1As in other fish and

9 CYP1A1s in mammals being highly active with this substrate [50-52]. The values we obtained

10 for EROD activity with CYP1A expressed via the pYES/DEST52 ranged from 89-150 pmol $\mathrm{min}^{-1}$

$11 \mathrm{mg}^{-1}$ yeast microsomal protein, similar to the optimum value of $142 \mathrm{pmol} \mathrm{min}^{-1} \mathrm{mg}^{-1} \mathrm{microsomal}$

12 protein obtained for zebrafish CYP1A expressed in another yeast strain, INVsc1, also using the

13 pYES/DEST52 destination vector [27].

14 CYP1C1, CYP1C2 and CYP1D1 expressed via the pYeDP60 vector had rates of activity

15 with a given resorufin substrate that were greater than rates obtained with the same enzymes

16 expressed via pYES/DEST52, However, we also observed very similar profiles of relative

17 activity with the resorufin substrates for the enzymes expressed via the different vectors,

18 analyzed in different laboratories. The relative rates of activity with the resorufin substrates we

19 observed with the CYP1s expressed in yeast were in large part similar to the relative activity

20 profiles with these substrates, for the same five zebrafish CYP1s expressed in E. coli [29]. In

21 particular, the substrate profiles for recombinant CYP1As from $\mathrm{W}(\mathrm{R})$ yeast and $E$. coli were

22 essentially the same. The CYP1B1, CYP1Cs and CYP1D1 showed some differences between

23 the yeast and E. coli recombinant enzymes. For example, as before [17] we found that CYP1D1

24 acted on 7-MR as well as 7-ER, while activity with 7-MR was not detected with CYP1D1

25 expressed in E. coli [29].

26 The redox partner for $\mathrm{P} 450$ in the $\mathrm{W}(\mathrm{R})$ yeast was the native yeast POR, while in the $E$. coli 
1 preparations it was the human POR enzyme [29]s. Differences in reductase identity might

2 contribute to differences in activity of a CYP with some substrates, perhaps especially evident at

3 rates that are very low. Differences in specific content of POR in the preparations of $E$. coli and

4 yeast also could contribute to differences in observed activity of recombinant CYP1s.

5 Nevertheless, the similarities in relative activities between the enzymes expressed in yeast

6 transformed via different vectors, and the similarities between yeast- and E. coli-expressed

7 enzymes, indicate that these relative activities reflect real differences in substrate selectivity for

8 the zebrafish CYP1 enzymes.

9 Cytochrome P450 was detected spectrophotometrically in microsomal preparations of the 10 yeast expressing CYP1C1, CYP1C2 and CYP1D1 via pYeDP60, but not in yeast transformed

11 via pYES/DEST52. The lack of a spectral P450 signal in the yeast transformed via

12 pYES/DEST52 could occur if there were substantially lower levels of expression with that

13 vector. Weaker expression in the yeast transformed with the pYES/DEST52 vector possibly

14 could result from some interference by the V5 tag. The V 5 tag also might interfere with the

15 activity of the expressed enzymes. The fact that the pYeDP60 vector contains two selection

16 markers also might contribute to higher levels of expression with that vector. Apparent

17 differences in expression also could involve some artifact resulting from differences in the

18 method of cell disruption [27], which was more vigorous with the pYES/DEST52 yeast.

19 However, a more likely possibility is that untranslated sequence at the 5' of the coding sequence

20 between the initiation ATG and the last bp of the GAL promoter is detrimental for translation

21 efficiency of P450-coding sequence [53]. There is an untranslated stretch between the inserted

22 coding sequence and the end of the GAL promoter in pYES/DEST52, but not in CYP1C1,

23 CYP1C2 and CYP1D1 constructs in pYeDP60.

24 As the spectrophotometric and catalytic assays indicated that the transformation of yeast via

25 pYeDP60 resulted in greater levels of expression of CYP1C1, CYP1C2 and CYP1D1,

26 microsomal preparations from these yeasts were used for further characterization of these 
1 CYP1s with additional fluorogenic substrates typically metabolized by CYP1s from mammalian

2 systems [49]. The three pYeDP60-expressed zebrafish CYP1s differed markedly from one

3 another with these substrates. Thus, EFEE and the substituted coumarins all were metabolized

4 more efficiently by CYP1C1 than by CYP1C2, a pattern opposite to that seen for EROD.

5 Notably, the CYP1D1 yeast microsomes showed no activity with any of these substrates.

6 Scornaienchi et al [29] also assayed the CYP1s expressed in E. coli for activity with a series of

7 substituted coumarins, but only one compound (7-methoxy-4-trifluoromethyl-coumarin) was

8 assayed in common in their series and ours. This compound was not a substrate for O-

9 dealkylation reactions by CYP1D1 expressed in yeast or E. coli. Despite the lack of O-

10 dealkylation activity, some coumarinic compounds appear to be susceptible to hydroxylation by

11 CYP1D1 (unpublished); further examination may suggest a functional significance for CYP1D1.

12 Ratios of activity with different substrates can reveal whether a novel CYP1 is more like

13 mammalian CYP1A1, CYP1A2, or CYP1B1. Based on the EROD/MROD ratios, CYP1C2 is an

14 "exacerbated" 1A1-type (ratio = 10.6; human CYP1A1 has an EROD/MROD ratio of 2.0,

15 Consistent with that, the $\mathrm{k}_{\text {cat }}$ for EROD determined with CYP1C2 is higher than the $\mathrm{k}_{\text {cat }}$ for

16 recombinant human CYP1A1 measured in our studies [54]. The high level of activity with EFEE

17 also suggests that CYP1C2 is a 1A1-type enzyme. In contrast, CYP1C1 and CYP1D1 have

18 EROD/MROD ratios that are more "1A2-type" (ratio = 1.3 and 1.1, respectively; human CYP1A2

19 has an EROD/MROD ratio of 0.6. CYP1D1 is also a 1A2-type, in that neither human CYP1A2

20 nor zebrafish CYP1D1 had activity with EFEE. However, CYP1C1, which is more 1A2-type

21 based on its EROD/MROD ratio, has 1A1-type characteristics based on high activity with EFEE.

\section{4.2. Benzo[a]pyrene and testosterone}

23 The rates we obtained with the radiometric assay for overall BaP metabolism by CYP1C1

24 and CYP1C2 were 0.81 and $2.26 \mathrm{nmol} / \mathrm{min} / \mathrm{nmol} \mathrm{P450,} \mathrm{respectively,} \mathrm{indicating} \mathrm{that} \mathrm{CYP1C2} \mathrm{is}$

25 more efficient at metabolism of this PAH than is CYP1C1. The ratio of CYP1C2 BaP metabolism

26 to CYP1C1 BaP metabolism per nmol P450 in the radiometric assay was 2.79 , and a similar 
1 CYP1C2/CYP1C1 ratio of 2.4 was obtained from the sum of metabolites formed, when

2 normalized to P450 (see Table 4). The rates of metabolism we measured with the radiometric

3 assay were somewhat greater than the overall rates for BaP metabolism reported for CYP1C1

4 and CYP1C2 expressed in E. coli, calculated from the sum of amounts of individual metabolites

5 [29]. However, in E. coli as in yeast, CYP1C2 was more active than CYP1C1 with BaP. That

6 CYP1C2 is more efficient than CYP1C1 at metabolism of BaP is consistent with the observation

7 from EROD data that CYP1C2 is catalytically more like mammalian CYP1A1. The amounts of

8 BaP metabolites formed, and the Ki for EROD inhibition, showed that BaP was a poor substrate

9 for the yeast-expressed CYP1D1, observed also with the E. coli-expressed CYP1D1 [29].

10 Both of the CYP1Cs expressed in yeast were formed the benzo-ring 7,8- and 9,10-

11 dihydrodiols of BaP. The CYP1Cs and the CYP1A and CYP1B1 expressed in E. coli also

12 formed benzo-ring dihydrodiols of $\mathrm{BaP}$ [29]. The metabolite results are supported by the

13 orientation of BaP docked into homology models of these four zebrafish CYP1s, all of which had

14 top poses with the benzo-ring oriented toward the heme iron. In contrast, the CYP1D1

15 expressed either in yeast or E.coli did not form the benzo-ring dihydrodiols, and docking to

16 CYP1D1 models showed a very different suite of poses than observed in the other CYP1s.

17 We also observed formation of BaP-7,8,9,10-tetrol by both CYP1Cs and by CYP1D1. The

18 BaP-7,8,9,10-tetrol reflects formation of the BaP-7,8-diol-9,10-oxides, which include the ultimate

19 carcinogenic derivative of BaP [55]. This suggests that metabolism by the CYP1Cs and

20 CYP1D1 could contribute to activation of BaP to mutagenic or carcinogenic diol-epoxides of

$21 \mathrm{BaP}$, although the lesser affinity of BaP for CYP1D1 suggests it may play less of a role than the

22 CYP1Cs. It has been known for many years that various fish tissues are able to oxidize BaP to

23 suites of metabolites, favoring oxidation both on the benzo-ring and at the 3-carbon (e.g [56]).

24 Our results suggest that the CYP1Cs could contribute significantly to overall metabolism of BaP

25 observed with microsomal preparations of organs or cells where these proteins might be

26 expressed abundantly; based on mRNA transcript levels this could include embryos. 
1 Determining patterns of metabolism of other PAH by these CYP1s will be important to

2 assessing their possible contribution to PAH effects in the zebrafish model.

3 As with BaP, CYP1D1 was much less active at overall metabolism of testosterone than the

4 CYP1Cs. A similar difference was observed for estradiol metabolism by the E. coli expressed

5 enzymes [28]. Thus, CYP1D1 is less active than the CYP1Cs with both androstane- and

6 estrane-derived compounds. While the CYP1Cs both formed 6ß-hydroxytestosterone CYP1D1

7 did not. Rather, in contrast to 6ß-hydroxylation, testosterone metabolite 1 was formed more

8 actively by CYP1D1 than the CYP1Cs. A difference between CYP1D1 and the CYP1Cs was

9 evident as well in the orientation of testosterone docked into the homology models. Generally,

10 the CYP3 family enzymes are the major catalysts for testosterone 6ß-hydroxylation in fish [57-

11 59]. That does not preclude other enzymes, such as the CYP1Cs, from contributing to this

12 metabolism, particularly in cells or life stages where CYP3As might be expressed weakly

13 relative to these CYP1s. Thus, the oxidation of testosterone by the three CYP1Cs or CYP1D1

14 could be physiologically relevant in some organs, cell types, or developmental stages.

15 The contribution of CYP1Cs relative to that of CYP1A or CYP1B1 to overall catalytic activity

16 is yet to be established in most organs in fish. Our studies on inhibition of EROD by a

17 monoclonal antibody to fish CYP1A indicate that, at least in liver of some fish species, about 95

$18 \%$ of microsomal EROD activity is due to CYP1A [52], implying little contribution from other

19 enzymes, and likely low level expression of the other CYP1s in liver overall. There could be

20 high-level expression of the other CYP1s in some cell type(s), but with rare exception (e.g., [60-

21 62]), there is as yet little information on the levels of the CYP1 proteins other than CYP1A in

22 different organs or cell types of fish, including throughout development. Such information can

23 point to the contribution of the various CYP1s to cell and organ responses to xenobiotic or

24 endogenous substrates in fish models such as zebrafish, exemplified by the reported

25 participation of CYP1Cs in TCDD effects in brain vessels [62]. 


\section{5. Conclusions}

The five CYP1s of zebrafish were expressed in yeast, and activities assessed with

3 substituted resorufins. The results with yeast-expressed enzymes were largely similar to results

4 with E. coli expressed zebrafish CYP1s [29], indicating that the recombinant enzymes from both

5 expression systems can give valid information about the functional capabilities of the zebrafish

6 CYP1s. As a general finding CYP1D1 tended to have less activity with most substrates than the

7 other CYP1s. This also was found with E. coli-expressed enzymes [29]. However, the formation

8 of a novel testosterone metabolite suggests there could be unrecognized biological functions of

9 CYP1D1. It also may be that the biological importance of CYP1D1 is diminishing over evolution,

10 suggested by the loss or pseudogenization of the CYP1D1 gene in some vertebrates [20, 63].

11 Results obtained with docking of BaP and testosterone to homology models of the CYP1s

12 were consistent with the metabolite data on sites of oxidation of these substrates. The approach

13 thus may be used to predict the regioselectivity of metabolism of substrates with multiple sites of

14 oxidation. It is important to note, however, that the docking here does not consider possible

15 differences in access channels that can govern substrate ingress to the active center [64].

16 Studies are underway to identify activities with other endogenous and xenobiotic substrates,

17 which will be important to inferring the roles of these multiple CYP1s in physiology and

18 toxicology in the zebrafish model. The functions of different CYP1s in vivo will also depend on

19 the relative levels of CYP1 protein expression, including the response to inducers, in different

20 organs and cell types, and at different developmental stages. Important questions remain

21 regarding the extent to which the multiple CYP1s might participate in the toxic effects of AHR

22 agonists, which tend also to be CYP1 substrates or inhibitors. The finding of substantial catalytic

23 function for the CYP1Cs with some substrates, as well as uncoupling of the CYP1Cs by

24 halogenated AHR agonists (unpublished observations), suggests that there could be a complex

25 involvement of multiple CYP1s in effects of AHR agonists in zebrafish. These CYP1s also

26 present an interesting opportunity for further exploring the structural features associated with 
1 substrate selectivity among related P450s. The full range of substrates of zebrafish CYP1s is

2 yet to be established, with either the E. coli or yeast expressed enzymes. Determining activities

3 with endogenous and xenobiotic substrates is important to inferring the roles of these multiple

4 CYP1s in health and disease in the zebrafish model.

5

6 


\section{Acknowledgments}

2 This work was supported in part by NIH grants R01ES015912 and P42ES007381 (the

3 Superfund Research Program at Boston University) to JJS, and the Centre National de la

4 Recherche Scientifique, France, by the Japan Society for the Promotion of Science Postdoctoral

5 Fellowship and Postdoctoral Fellowship for Research Abroad to AK (JSPS nos. 194313 and

624820 , respectively), and by a Belgian-American Educational Foundation (BAEF) Postdoctoral

7 Fellowship (BL). Additional support (JJS) was provided by NIH grant P01ES021923 and

8 National Science Foundation Grant OCE-1314642 through the Woods Hole Center for Oceans

9 and Human Health. NAMD was developed by the Theoretical and Computational Biophysics

10 Group in the Beckman Institute for Advanced Science and Technology at the University of

11 Illinois at Urbana-Champaign. 


\section{References}

1. Ioannides, C. and D.F. Lewis, Cytochromes P450 in the bioactivation of chemicals. Curr Top Med Chem, 2004. 4(16): p. 1767-88.

2. Nebert, D.W. and T.P. Dalton, The role of cytochrome P450 enzymes in endogenous

3. Gonzalez, F.J. and S. Kimura, Understanding the role of xenobiotic-metabolism in chemical carcinogenesis using gene knockout mice. Mutat Res, 2001. 477(1-2): p. 79-87.

4. Kleiner, H.E., S.V. Vulimiri, W.B. Hatten, M.J. Reed, D.W. Nebert, C.R. Jefcoate, and J. DiGiovanni, Role of cytochrome p4501 family members in the metabolic activation of polycyclic aromatic hydrocarbons in mouse epidermis. Chem Res Toxicol, 2004. 17(12): p. 1667-74.

5. Nebert, D.W. and D.W. Russell, Clinical importance of the cytochromes P450. The Lancet, 2002. 360: p. 1155-1162.

6. Guengerich, F.P., Cytochrome p450 and chemical toxicology. Chem Res Toxicol, 2008. 21(1): p. 70-83.

7. Guengerich, F.P., Human cytochrome P450 enzymes, in Cytochrome P450: Structure, Mechanism, and Biochemistry, P.R. Ortiz de Montellano, Editor. 2005, Kluwer Academic: New York. p. 377-463.

8. Kim, D. and F.P. Guengerich, Cytochrome $P 450$ activation of arylamines and heterocyclic amines. Annu Rev Pharmacol Toxicol, 2005. 45: p. 27-49.

9. Dragin, N., Z. Shi, R. Madan, C.L. Karp, M.A. Sartor, C. Chen, F.J. Gonzalez, and D.W. Nebert, Phenotype of the Cyp1a1/1a2/1b1-/- triple-knockout mouse. Mol Pharmacol, 2008. 73(6): p. 1844-56.

10. Schwarz, D., P. Kisselev, A. Chernogolov, W.H. Schunck, and I. Roots, Human CYP1A1 variants lead to differential eicosapentaenoic acid metabolite patterns. Biochem Biophys Res Commun, 2005. 336(3): p. 779-83.

11. Schwarz, D., P. Kisselev, S.S. Ericksen, G.D. Szklarz, A. Chernogolov, H. Honeck, W.H. Schunck, and I. Roots, Arachidonic and eicosapentaenoic acid metabolism by human CYP1A1: highly stereoselective formation of 17(R),18(S)-epoxyeicosatetraenoic acid. Biochem Pharmacol, 2004. 67(8): p. 1445-57. 
12. Schlezinger, J.J., C. Parker, D.C. Zeldin, and J.J. Stegeman, Arachidonic acid metabolism in the marine fish Stenotomus chrysops (Scup) and the effects of cytochrome P450 1A inducers. Arch Biochem Biophys, 1998. 353(2): p. 265-75.

13. Rifkind, A.B., C. Lee, T.K. Chang, and D.J. Waxman, Arachidonic acid metabolism by human cytochrome P450s 2C8, 2C9, 2E1, and 1A2: regioselective oxygenation and evidence for a role for CYP2C enzymes in arachidonic acid epoxygenation in human liver microsomes. Arch Biochem Biophys, 1995. 320(2): p. 380-9.

14. Nebert, D.W., T.P. Dalton, A.B. Okey, and F.J. Gonzalez, Role of aryl hydrocarbon receptormediated induction of the CYP1 enzymes in environmental toxicity and cancer. J Biol Chem, 2004. 279(23): p. 23847-50.

15. Uno, T., S. Okamoto, S. Masuda, H. Imaishi, M. Nakamura, K. Kanamaru, H. Yamagata, M.A. El-Kady, Y. Kaminishi, and T. Itakura, Bioconversion by functional P450 1 A9 and P450 1C1 of Anguilla japonica. Comp Biochem Physiol C Toxicol Pharmacol, 2008. 147(3): p. 278-85.

16. Godard, C.A., J.V. Goldstone, M.R. Said, R.L. Dickerson, B.R. Woodin, and J.J. Stegeman, The new vertebrate CYP1C family: cloning of new subfamily members and phylogenetic analysis. Biochem Biophys Res Commun, 2005. 331(4): p. 1016-1024.

17. Goldstone, J.V., M.E. Jönsson, L. Behrendt, B.R. Woodin, M.J. Jenny, D.R. Nelson, and J.J. Stegeman, Cytochrome P450 1D1: a novel CYP1A-related gene that is not transcriptionally activated by PCB126 or TCDD. Arch Biochem Biophys, 2009. 482(1-2): p. 7-16.

18. Goldstone, J.V., H.M. Goldstone, A.M. Morrison, A. Tarrant, S.E. Kern, B.R. Woodin, and J.J. Stegeman, Cytochrome P450 1 genes in early deuterostomes (tunicates and sea urchins) and vertebrates (chicken and frog): origin and diversification of the CYP1 gene family. Mol Biol Evol, 2007. 24(12): p. 2619-31.

19. Jonsson, M.E., C. Berg, J.V. Goldstone, and J.J. Stegeman, New CYP1 genes in the frog Xenopus (Silurana) tropicalis: induction patterns and effects of AHR agonists during development. Toxicol Appl Pharmacol, 2010. 250(2): p. 170-83.

20. Jonsson, M.E., B.R. Woodin, J.J. Stegeman, and B. Brunstrom, Cytochrome p450 1 genes in birds: evolutionary relationships and transcription profiles in chicken and Japanese quail embryos. PLoS One, 2011. 6(12): p. e28257.

21. Stegeman, J.J., J.V. Goldstone, and M.E. Hahn, Perspectives on zebrafish as a model in environmental toxicology, in Zebrafish, S.F. Perry, et al., Editors. 2010, Academic Press: New York. p. 367-439. 
22. Mandrell, D., L. Truong, C. Jephson, M.R. Sarker, A. Moore, C. Lang, M.T. Simonich, and R.L. Tanguay, Automated zebrafish chorion removal and single embryo placement: optimizing throughput of zebrafish developmental toxicity screens. J Lab Autom, 2012. 17(1): p. 66-74.

23. Peterson, R.T. and C.A. Macrae, Systematic approaches to toxicology in the zebrafish. Annu Rev Pharmacol Toxicol, 2012. 52: p. 433-53.

24. Jönsson, M.E., R. Orrego, B.R. Woodin, J.V. Goldstone, and J.J. Stegeman, Basal and 3,3',4,4',5-pentachlorobiphenyl-induced expression of cytochrome P450 1A, 1B and 1C genes in zebrafish. Toxicol Appl Pharmacol, 2007. 221(1): p. 29-41.

25. Wang, L., B.E. Scheffler, and K.L. Willett, CYP1C1 messenger RNA expression is inducible by benzo[a]pyrene in Fundulus heteroclitus embryos and adults. Toxicol Sci, 2006. 93(2): p. 331-40.

26. Jonsson, M.E., M.J. Jenny, B.R. Woodin, M.E. Hahn, and J.J. Stegeman, Role of AHR2 in the expression of novel cytochrome P450 1 family genes, cell cycle genes, and morphological defects in developing zebra fish exposed to 3,3',4,4',5-pentachlorobiphenyl or 2,3,7,8-tetrachlorodibenzo-p-dioxin. Toxicol Sci, 2007. 100(1): p. 180-93.

27. Chung, W.G., A. Sen, J.L. Wang-Buhler, Y.H. Yang, N. Lopez, G.F. Merrill, C.L. Miranda, C.H. Hu, and D.R. Buhler, cDNA-directed expression of a functional zebrafish CYP1A in yeast. Aquat Toxicol, 2004. 70(2): p. 111-21.

28. Scornaienchi, M.L., C. Thornton, K.L. Willett, and J.Y. Wilson, Cytochrome P450-mediated 17beta-estradiol metabolism in zebrafish (Danio rerio). J Endocrinol, 2010. 206(3): p. 31725.

29. Scornaienchi, M.L., C. Thornton, K.L. Willett, and J.Y. Wilson, Functional differences in the cytochrome P450 1 family enzymes from zebrafish (Danio rerio) using heterologously expressed proteins. Arch Biochem Biophys, 2010. 502(1): p. 17-22.

30. Truan, G., C. Cullin, P. Reisdorf, P. Urban, and D. Pompon, Enhanced in vivo monooxygenase activities of mammalian P450s in engineered yeast cells producing high levels of NADPH-P450 reductase and human cytochrome b5. Gene, 1993. 125(1): p. 49-55.

31. Gietz, R.D. and R.A. Woods, Transformation of yeast by lithium acetate/single-stranded carrier DNA/polyethylene glycol method. Methods Enzymol, 2002. 350: p. 87-96.

32. Pompon, D., B. Louerat, A. Bronine, and P. Urban, Yeast expression of animal and plant P450s in optimized redox environments. Methods Enzymol, 1996. 272: p. 51-64. 
33. Urban, P., G. Truan, A. Bellamine, R. Laine, J.C. Gautier, and D. Pompon, Engineered yeasts simulating P450-dependent metabolisms: tricks, myths and reality. Drug Metabol Drug Interact, 1994. 11(3): p. 169-200.

34. Smith, P.K., R.I. Krohn, G.T. Hermanson, A.K. Mallia, F.H. Gartner, M.D. Provenzano, E.K. Fujimoto, N.M. Goeke, B.J. Olson, and D.C. Klenk, Measurement of protein using bicinchoninic acid. Anal Biochem, 1985. 150(1): p. 76-85.

35. Hahn, M.E., T.M. Lamb, M.E. Schultz, R.M. Smolowitz, and J.J. Stegeman, CytochromeP4501a Induction and Inhibition by 3,3',4,4'-Tetrachlorobiphenyl in an Ah ReceptorContaining Fish Hepatoma-Cell Line (PIhc-1). Aquat Toxicol, 1993. 26(3-4): p. 185-208.

36. Kennedy, S.W., A. Lorenzen, C.A. James, and B.T. Collins, Ethoxyresorufin-O-Deethylase and Porphyrin Analysis in Chicken-Embryo Hepatocyte Cultures with a Fluorescence Multiwell Plate Reader. Anal Biochem, 1993. 211(1): p. 102-112.

37. Binder, R.L. and J.J. Stegeman, Induction of aryl hydrocarbon hydroxylase activity in embryos of estuarine fish. Biochem Pharmacol, 1980. 29(6): p. 949-51.

38. Eswar, N., B. Webb, M.A. Marti-Renom, M.S. Madhusudhan, D. Eramian, M.Y. Shen, U. Pieper, and A. Sali, Comparative protein structure modeling using MODELLER. Curr Protoc Protein Sci, 2007. Chapter 2: p. Unit 29.

39. Sansen, S., J.K. Yano, R.L. Reynald, G.A. Schoch, K.J. Griffin, C.D. Stout, and E.F. Johnson, Adaptations for the oxidation of polycyclic aromatic hydrocarbons exhibited by the structure of human P450 1A2. J Biol Chem, 2007. 282(19): p. 14348-55.

40. Wang, A., U. Savas, C.D. Stout, and E.F. Johnson, Structural characterization of the complex between alpha-naphthoflavone and human cytochrome P450 1B1. J Biol Chem, 2011. 286(7): p. 5736-43.

41. Phillips, J.C., R. Braun, W. Wang, J. Gumbart, E. Tajkhorshid, E. Villa, C. Chipot, R.D. Skeel, L. Kale, and K. Schulten, Scalable molecular dynamics with NAMD. J Comput Chem, 2005. 26(16): p. 1781-802.

42. Cosconati, S., S. Forli, A.L. Perryman, R. Harris, D.S. Goodsell, and A.J. Olson, Virtual Screening with AutoDock: Theory and Practice. Expert Opin Drug Discov, 2011. 5(6): p. 597-607.

43. Stewart, J.J., Optimization of parameters for semiempirical methods V: modification of NDDO approximations and application to 70 elements. J Mol Model, 2007. 13(12): p. 1173213.

44. Stewart, J.J., MOPAC2009. 2008, Stewart Computational Chemistry: Colorado Springs, CO. 
45. Trott, O. and A.J. Olson, AutoDock Vina: improving the speed and accuracy of docking with a new scoring function, efficient optimization, and multithreading. J Comput Chem, 2009. 31(2): p. 455-61.

46. Peyronneau, M.A., J.P. Renaud, M. Jaouen, P. Urban, C. Cullin, D. Pompon, and D.

Mansuy, Expression in yeast of three allelic cDNAs coding for human liver P-450 3A4. Different stabilities, binding properties and catalytic activities of the yeast-produced enzymes. Eur J Biochem, 1993. 218(2): p. 355-61.

47. Urban, P., C. Mignotte, M. Kazmaier, F. Delorme, and D. Pompon, Cloning, yeast expression, and characterization of the coupling of two distantly related Arabidopsis thaliana NADPH-cytochrome P450 reductases with P450 CYP73A5. J Biol Chem, 1997. 272(31): p. 19176-86.

48. Urban, P., D. Werck-Reichhart, H.G. Teutsch, F. Durst, S. Regnier, M. Kazmaier, and D. Pompon, Characterization of recombinant plant cinnamate 4-hydroxylase produced in yeast. Kinetic and spectral properties of the major plant P450 of the phenylpropanoid pathway. Eur J Biochem, 1994. 222(3): p. 843-50.

49. Taly, V., P. Urban, G. Truan, and D. Pompon, A combinatorial approach to substrate discrimination in the P450 CYP1A subfamily. Biochim Biophys Acta, 2007. 1770(3): p. 44657.

50. Bellamine, A., J.C. Gautier, P. Urban, and D. Pompon, Chimeras of the human cytochrome P450 1A family produced in yeast. Accumulation in microsomal membranes, enzyme kinetics and stability. Eur J Biochem, 1994. 225(3): p. 1005-13.

51. Burke, M.D., R.A. Prough, and R.T. Mayer, Characteristics of a microsomal cytochrome P448-mediated reaction. Ethoxyresorufin O-de-ethylation. Drug Metab Dispos, 1977. 5(1): p. 1-8.

52. Kloepper-Sams, P.J., S.S. Park, H.V. Gelboin, and J.J. Stegeman, Specificity and crossreactivity of monoclonal and polyclonal antibodies against cytochrome P-450E of the marine fish scup. Arch Biochem Biophys, 1987. 253(1): p. 268-78.

53. Pompon, D., cDNA cloning and functional expression in yeast Saccharomyces cerevisiae of beta-naphthoflavone-induced rabbit liver P-450 LM4 and LM6. Eur J Biochem, 1988. 177(2): p. 285-93.

54. Gautier, J.C., P. Urban, P. Beaune, and D. Pompon, Engineered yeast cells as model to study coupling between human xenobiotic metabolizing enzymes. Simulation of the two first steps of benzo[a]pyrene activation. Eur J Biochem, 1993. 211(1-2): p. 63-72. 
55. Ma, Q. and A.Y. Lu, CYP1A induction and human risk assessment: an evolving tale of in vitro and in vivo studies. Drug Metab Dispos, 2007. 35(7): p. 1009-16.

56. Stegeman, J.J., B.R. Woodin, and R.L. Binder, Patterns of benzo[a]pyrene metabolism by varied species, organs, and developmental stages of fish. Natl Cancer Inst Monogr, 1984.

57. Klotz, A.V., J.J. Stegeman, B.R. Woodin, E.A. Snowberger, P.E. Thomas, and C. Walsh, Cytochrome P-450 isozymes from the marine teleost Stenotomus chrysops: their roles in steroid hydroxylation and the influence of cytochrome b5. Arch Biochem Biophys, 1986. 249(2): p. 326-38.

58. Celander, M., D.R. Buhler, L. Forlin, A. Goksoyr, C.L. Miranda, B.R. Woodin, and J.J. Stegeman, Immunochemical relationships of cytochrome P4503A-like proteins in teleost fish. Fish Physiol Biochem, 1996. 15(4): p. 323-32.

59. Lee, S.J. and D.R. Buhler, Functional properties of a rainbow trout CYP3A27 expressed by recombinant baculovirus in insect cells. Drug Metab Dispos, 2002. 30(12): p. 1406-12.

60. Bugiak, B. and L.P. Weber, Hepatic and vascular mRNA expression in adult zebrafish (Danio rerio) following exposure to benzo-a-pyrene and 2,3,7,8-tetrachlorodibenzo-p-dioxin. Aquat Toxicol, 2009. 95(4): p. 299-306.

61. Wang, L., A.C. Camus, W. Dong, C. Thornton, and K.L. Willett, Expression of CYP1C1 and CYP1A in Fundulus heteroclitus during PAH-induced carcinogenesis. Aquat Toxicol, 2010. 99(4): p. 439-47.

62. Kubota, A., J.J. Stegeman, B.R. Woodin, T. Iwanaga, R. Harano, R.E. Peterson, T. Hiraga, and $\mathrm{H}$. Teraoka, Role of zebrafish cytochrome P450 CYP1C genes in the reduced mesencephalic vein blood flow caused by activation of AHR2. Toxicol Appl Pharmacol, 2011. 253(3): p. 244-52.

63. Kawai, Y.K., Y. Ikenaka, S. Fujita, and M. Ishizuka, The CYP1D subfamily of genes in mammals and other vertebrates. Mamm Genome, 2010. 21(5-6): p. 320-9.

64. Urban, P., G. Truan, and D. Pompon, Access channels to the buried active site control substrate specificity in CYP1A P450 enzymes. Biochim Biophys Acta, 2015. 1850(4): p. 696-707. 
Figure legends

Figure 1. Structures of substrates tested for activity with zebrafish CYP1s.

Figure 2. Zebrafish CYP1s expressed via pYES/DEST52 in yeast. Immunodetection with antibodies to the V5-tag. Each lane had $5 \mu \mathrm{g}$ of microsomal protein loaded: lane 1, CYP1A; lane 2, CYP1B1; lane 3, CYP1C1; lane 4, CYP1C2; lane 5, CYP1D1; lane 6, mol wt standards.

Figure 3. Relative rates of microsomal alkoxy-O-dealkylase activities of zebrafish CYP1s expressed in yeast. For each CYP, the activities with 7-ER (EROD) are set at 100\%. The enzymes expressed via pYES/DEST52 are in the left column, and for CYP1Cs and CYP1D1 expressed via pYeDP60 are in the right column. The error bars reflect error propagation.

11 Figure 4. Spectral analysis of recombinant CYP1C1. Reduced, CO difference spectrum

12 obtained with yeast microsomes transformed with CYP1C1 expressed via pYeDP60.

13 Figure 5. Benzo[a]pyrene metabolite profiles for CYP1Cs and CYP1D1. Panel A,

14 microsomal specific acitivity calculated for each benzo[a]pyrene metabolite from its peak area

15 (arbitrary units) expressed per min and per mg of yeast microsomal protein. The retention times 16 of the different compounds were tetrol (3.2 $\mathrm{min}), 9,10$-dhydrodiol (4.2 $\mathrm{min}), 7,8$-dihydrodiol (5.6

$17 \mathrm{~min}$ ), 9-hydroxy (7.9 min), 3-hydroxy (8.3 $\mathrm{min})$, and benzo[a]pyrene (11.0 $\mathrm{min}$ ) for a total run

18 time of 14 min. Panel B, benzo[a]pyrene metabolite profiles obtained for each CYP enzyme

19 from unit-scaling the specific activities to the highest one. For each CYP enzyme, bars

20 represent from left to right Tetrol, 9,10-dihydrodiol, 7,8-dihydrodiol, 9-hydroxy-, and 3-hydroxy-

21 benzo[a]pyrene metabolite.

22 Figure 6. Testosterone metabolite profiles for CYP1Cs and CYP1D1. Panel A, Microsomal

23 specific acitivity calculated for each testosterone metabolite from its peak area (arbitrary units)

24 expressed per min and per mg of yeast microsomal protein. The retention times of the different 
1 compounds were M1 (5.3 min), M2 (6.6 min), 6ß-hydroxy (7.1 min), and testosterone (8.1 min)

2 for a total run time of 14 min. Panel B, testosterone metabolite profiles obtained for each CYP

3 enzyme from unit-scaling the specific activities to the highest one. For each CYP enzyme, bars

4 represent from left to right, hydroxylated testosterone M1 (unknown), hydroxylated testosterone

5 M2 (unknown), 6ß-hydroxy-testosterone.

6 Figure 7. Best single positions for BaP docked in zebrafish CYP1s. Homology models for

7 the five CYP1s were constructed, and substrates docked as described in the Mathods section.

8 The benzo-ring is oriented in a productive position for all models except for CYP1D1.

9 Figure 8. Best single positions for testosterone docked in zebrafish CYP1s. Homology

10 models for the five CYP1s were constructed, and substrates docked as described in the

11 Mathods section. Note that the pose in CYP1D1 is different from top poses in the other CYP1s. 
Table 1. Activities of CYP1s expressed in yeast with resorufin and ethoxyfluorescein ethylester

Substrate $\quad$ CYP expressed via pYES/DEST52 ${ }^{a} \quad$ CYP expressed via pYeDP60 ${ }^{a}$

\begin{tabular}{lccc|c|c|c|c|c|c|} 
& \multicolumn{1}{c|}{$1 \mathrm{~A}$} & $1 \mathrm{~B} 1$ & $1 \mathrm{C} 1$ & $1 \mathrm{C} 2$ & $1 \mathrm{D} 1$ & $1 \mathrm{C} 1$ & $1 \mathrm{C} 2$ & $1 \mathrm{D} 1$ \\
\hline ER $^{\mathrm{d}}$ & $89.3 \pm 1.9$ & $0.2 \pm 0.2$ & $2.1 \pm 0.7$ & $46.5 \pm 2.0$ & $1.1 \pm 0.5$ & $757 \pm 60$ & $1301 \pm 13$ & $35 \pm 4$ \\
$\mathrm{MR}$ & $58.1 \pm 0.8$ & $0.4 \pm 0.1$ & $1.6 \pm 0.7$ & $2.2 \pm 0.7$ & $1.1 \pm 0.0$ & $567 \pm 69$ & $110 \pm 17$ & $31 \pm 3$ \\
$\mathrm{PR}$ & $1.3 \pm 0.3$ & $\mathrm{ND}^{\mathrm{b}}$ & $\mathrm{ND}$ & $\mathrm{ND}$ & $0.2 \pm 0.1$ & $27 \pm 6$ & $11 \pm 2$ & $14 \pm 5$ \\
$\mathrm{BR}$ & $6.3 \pm 0.3$ & $\mathrm{ND}$ & $0.3 \pm 0.3$ & $3.0 \pm 0.5$ & $0.3 \pm 0.2$ & $20 \pm 4$ & $124 \pm 11$ & $2.2 \pm 0.2$ \\
EFEE & $---{ }^{\mathrm{c}}$ & --- & --- & --- & --- & $78 \pm 4$ & $21 \pm 8$ & ND
\end{tabular}

${ }^{\text {a }}$ All activities are in pmol substrate oxidized $\mathrm{min}^{-1} \mathrm{mg}^{-1}$ microsomal protein. Each of these values is the mean of four to six different measurements. Boiled microsomes from each transformant and microsomes from yeast expressing Arabidopsis $\beta$-glucuronidase exhibited no catalytic activity with any substrate. The final concentration of methanol in incubation mixtures was $0.2-$ $0.3 \%$.

${ }^{\mathrm{b}} \mathrm{ND}$ is not detected.

${ }^{\mathrm{c}}$ Not assayed with CYPs expressed via pYES/DEST52.

${ }^{d}$ Abbreviations are ethoxy-, methoxy-, propyloxy- and benzyloxyresorufin (ER, MR, PR and BR) and 7-ethoxyfluorescein-ethylester (EFEE). 
Table 2. Km and Kcat for dealkylation of resorufin substrates

\begin{tabular}{|c|c|c|c|c|c|c|}
\hline Enzyme & $\begin{array}{c}\mathrm{Km} \text { for } \\
\mathrm{ER}(\mathrm{nM})\end{array}$ & & (mol subs & $\begin{array}{c}\text { Kcat } \\
\text { ate oxidized/r }\end{array}$ & ol P450/min) & \\
\hline & & $E R^{c}$ & MR & PR & BR & EFEE \\
\hline CYP1C1 & $85 \pm 5$ & $6.5 \pm 0.5$ & $4.9 \pm 0.6$ & $0.27 \pm 0.06$ & $0.20 \pm 0.04$ & $0.67 \pm 0.03$ \\
\hline CYP1C2 & $110 \pm 10$ & $35.1 \pm 0.4$ & $3.3 \pm 0.5$ & $0.30 \pm 0.06$ & $3.35 \pm 0.29$ & $0.40 \pm 0.15$ \\
\hline CYP1D1 & $1000^{a}$ & - & - & - & - & - \\
\hline
\end{tabular}

${ }^{a}$ Estimated from the specific activities expressed per mg of yeast microsomal protein, from yeast transformed via pYeDP60. Each of these values is the mean of four to eight different measurements. The final concentration of methanol was $0.2-0.3 \%$ for resorufins and $0.1 \%$ for EFEE assays.

${ }^{b}$ The P450 contents of the microsomal samples used for these assays were 0.12 and $0.04 \mathrm{nmol} / \mathrm{mg}$ for CYP1C1 and CYPC2, respectively. A P450 spectrum was detected in some CYP1D1 preparations, but not those that had been used in this analysis.

${ }^{\mathrm{c}}$ Abbreviations are as in Table 1. 
Table 3. Kcat values with coumarin substrates

\begin{tabular}{|l|c|c|c|c|c|}
\hline \multirow{2}{*}{} & \multicolumn{5}{|c|}{ kcat } \\
& \multicolumn{5}{|c|}{ (mol substrate oxidized/mol P450/min) $^{\mathrm{a}}$} \\
\hline Enzyme & $\mathrm{MOC}^{\mathrm{b}, \mathrm{c}}$ & $\mathrm{MMC}^{\mathrm{b}, \mathrm{c}}$ & $\mathrm{MBC}^{\mathrm{b}, \mathrm{c}}$ & $\mathrm{MFC}^{\mathrm{b}, \mathrm{c}}$ & EFC $^{\mathrm{c}, \mathrm{d}}$ \\
\hline CYP1C1 & $0.70,0.85$ & $1.35,1.11$ & $0.215,0.27$ & $0.36,0.43$ & $1.51 \pm 0.14$ \\
\hline CYP1C2 $^{*}$ & $0.29,0.36$ & $0.18,0.22$ & $0.04,0.06$ & $0.04,0.04$ & $1.18 \pm 0.02$ \\
\hline CYP1D1 $^{\mathrm{e}}$ & 0 & 0 & 0 & 0 & 0 \\
\hline
\end{tabular}

${ }^{a}$ Kcat values obtained with microsomal preparations from yeast expressing the indicated CYP via pYeDP60, and in which P450 content could be measured. The P450 contents in these preparations were were 0.12 and $0.04 \mathrm{nmol} / \mathrm{mg}$ for CYP1C1 and CYPC2, respectively. The final concentration of methanol (with all coumarins except $\mathrm{MBC}$ ) or DMF (MBC assays) was $0.2 \%$.

${ }^{\mathrm{b}}$ Abbreviations are: 7-methoxy-coumarin (MOC); 7-methoxy-4-methyl-coumarin (MMC);

7-methoxy-4-bromomethyl-coumarin (MBC); 7-methoxy-4-trifluoromethyl-coumarin (MFC); 7-ethoxy-4-trifluoromethyl-coumarin (EFC).

${ }^{\mathrm{c}}$ These values were obtained from measurements with two independent preparations, and both values are shown.

${ }^{\mathrm{d}}$ These values are from measurements with four to eight independent preparations.

${ }^{e}$ No dealkylation activity was detected with CYP1D1 for any of these substrates. 
Table 4. Benzo[a]pyrene Interaction with Zebrafish CYP1Cs and CYP1D1 Expressed in Yeast, and Metabolite Formation.

\begin{tabular}{|c|c|c|c|c|c|c|}
\hline & \multicolumn{6}{|c|}{ Benzo[a]pyrene metabolite ${ }^{b}$} \\
\hline & $\mathrm{K}_{\mathrm{i}}^{\mathrm{a}}$ & $\underline{\text { Tetrol }}$ & 9,10-diol & $\underline{\text { 7,8-diol }}$ & $\underline{9-\mathrm{OH}}$ & $\underline{3-\mathrm{OH}}$ \\
\hline CYP1C1 & $0.06 \mu \mathrm{M}$ & 0.223 & 0.179 & 0.082 & 1.000 & 0.456 \\
\hline CYP1C2 & $0.20 \mu \mathrm{M}$ & 0.099 & 0.040 & 0.064 & 0.421 & 0.926 \\
\hline CYP1D1 & $12 \mu \mathrm{M}$ & 0.007 & 0 & 0 & 0.023 & 0.015 \\
\hline
\end{tabular}

\footnotetext{
${ }^{a}$ Competitive inhibition of ethoxyresorufin O-deethylation reaction by benzo[a]pyrene.

${ }^{b}$ Metabolite formation is derived from mass spec (MS) peak areas expressed as arbitrary units $\mathrm{min}^{-1} \mathrm{mg}^{-1}$ microsomal protein, normalized to the highest MS peak area. Expressing the total metabolite formation to microsomal P450 content gave arbitrary units $\mathrm{min}^{-1} \mathrm{mg}^{-1} \mathrm{P} 450$ of 16.1 for CYP1C1 and 38.7 for CYP1C2, and a ratio of CYP1C2/CYP1C1 of 2.4.
} 
Table 5. Calculated Affinities and Relative $k_{D}$ Values from Docking Studies.

\begin{tabular}{lcccccc}
\hline & \multicolumn{3}{c}{ BaP } & & \multicolumn{3}{c}{ Testosterone } \\
& $\begin{array}{c}\text { Best affinity } \\
(\mathrm{kcal} / \mathrm{mol})\end{array}$ & $\begin{array}{c}\text { Mean } \\
\text { affinity }^{\mathrm{a}}\end{array}$ & $\begin{array}{c}\text { Relative } \\
\mathrm{k}_{\mathrm{D}}\end{array}$ & $\begin{array}{c}\text { Best affinity } \\
(\mathrm{kcal} / \mathrm{mol})\end{array}$ & $\begin{array}{c}\text { Mean } \\
\text { affinity }\end{array}$ & Relative \\
CYP1A & -14.5 & -14.3 & 0.026 & -11.6 & -9.5 & 0.127 \\
CYP1B1 & -14.4 & -14.2 & 0.035 & -10.5 & -8.3 & 1.000 \\
CYP1C1 & -14.1 & -13.7 & 0.072 & -11.0 & -8.9 & 0.363 \\
CYP1C2 & -15.1 & -14.9 & 0.011 & -11.6 & -8.5 & 0.713 \\
CYP1D1 & -12.5 & -12.2 & 1.000 & -10.7 & -9.9 & 0.065 \\
\hline
\end{tabular}

${ }^{\mathrm{a}}$ Mean of top 5 poses 
Class of resorufins<smiles>[R]Oc1ccc2c(c1)OC1=CC(=O)C=CC1N2</smiles>

$$
\begin{array}{ll}
\mathrm{R}=\mathrm{CH}_{3} & \text { 7-methoxyresorufin } \\
\mathrm{R}=\mathrm{CH}_{2} \mathrm{CH}_{3} & \text { 7-ethoxyresorufin } \\
\mathrm{R}=\left(\mathrm{CH}_{2}\right) 4 \mathrm{CH}_{3} & \text { 7-pentoxyresorufin } \\
\mathrm{R}=\mathrm{CH}_{2} \mathrm{C}_{5} \mathrm{H}_{6} & \text { 7-benzoxyresorufin }
\end{array}
$$

Class of coumarins<smiles>[R]Oc1ccc2c([R2])cc(=O)oc2c1</smiles>
$\mathrm{R} 1=\mathrm{CH} 3$,
$\mathrm{R} 2=\mathrm{H}$
7-methoxycoumarin
$\mathrm{R} 1=\mathrm{CH} 3$,
$\mathrm{R} 2=\mathrm{CH} 3$
7-methoxy-4-methylcoumarin
$\mathrm{R} 1=\mathrm{CH}_{3}$,
$\mathrm{R} 2=\mathrm{CH}_{2} \mathrm{Br}$
7-methoxy-4-bromomethylcoumarin
$\mathrm{R} 1=\mathrm{CH}_{2} \mathrm{CH}_{3}, \mathrm{R} 2=\mathrm{CF}_{3}$
7-ethoxy-4-trifluoromethylcoumarin

Class of fluorescein<smiles>CCOC(=O)c1ccccc1-c1c2ccc(=O)cc-2oc2cc(OCC)ccc12</smiles>

7-ethoxy-fluorescein-ethylester

Benzo[a]pyrene<smiles>c1ccc2c(c1)cc1ccc3cccc4ccc2c1c34</smiles>

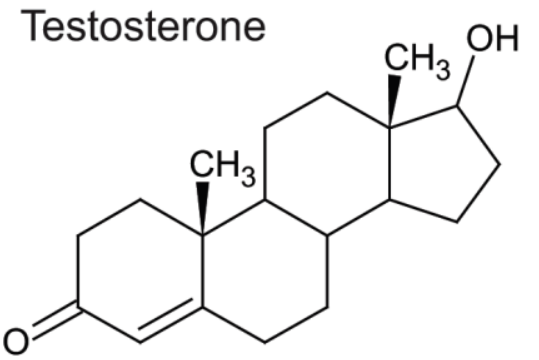


$\begin{array}{llllll}1 & 2 & 3 & 4 & 5 & 6\end{array}$

Figure 2

\section{$\therefore-60 \mathrm{kDa}$ \\ $-50 \mathrm{kDa}$ \\ $-40 \mathrm{kDa}$ \\ $\ldots-30 \mathrm{kDa}$




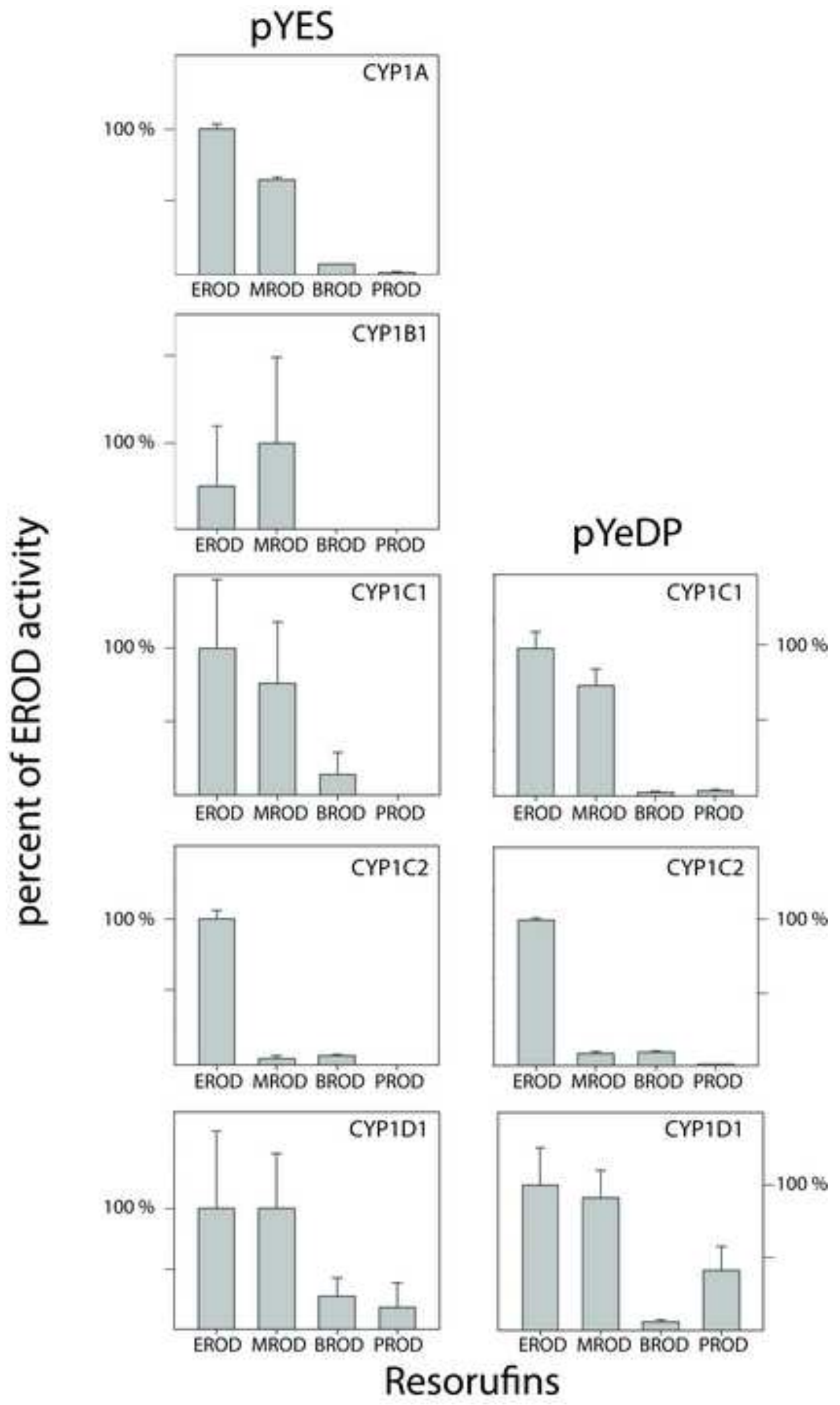




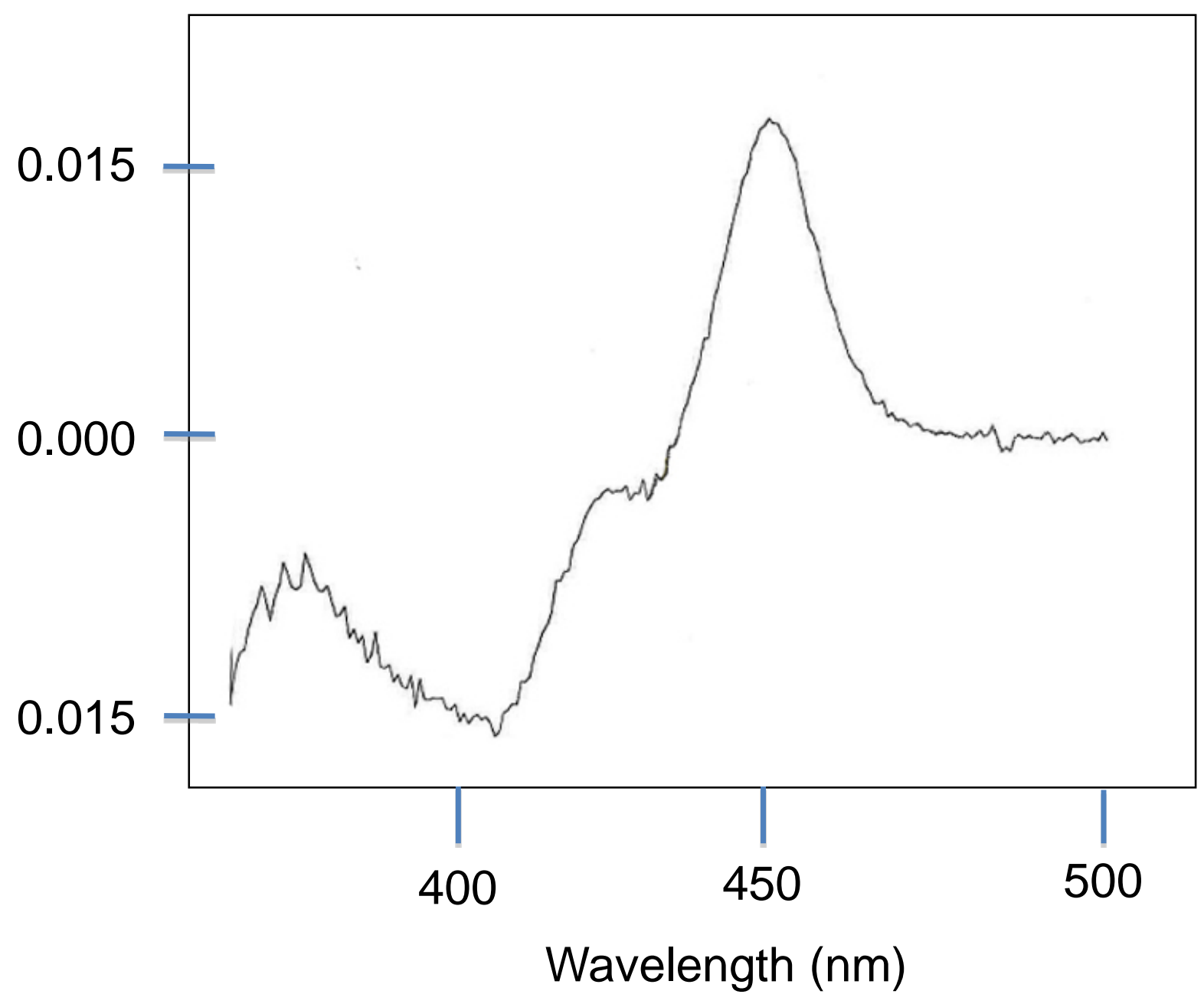


Figure 5

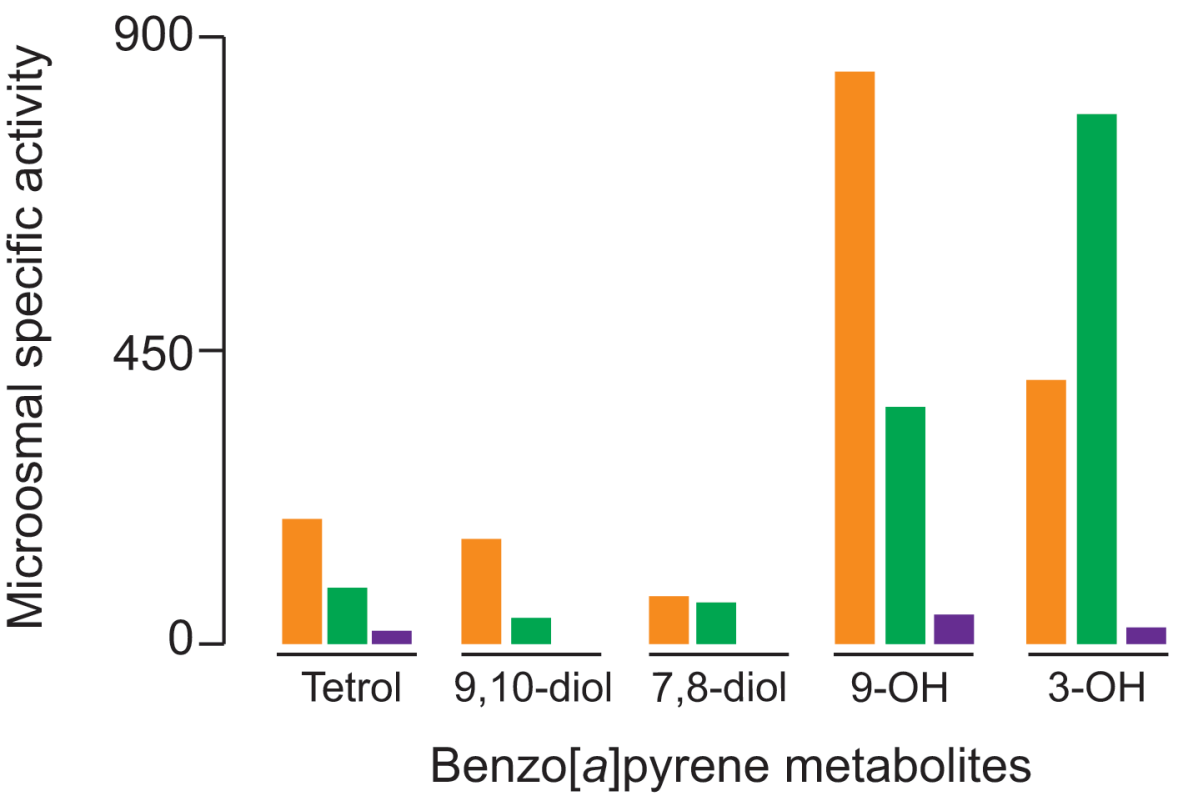

CYP1C1

CYP1C2

CYP1D1
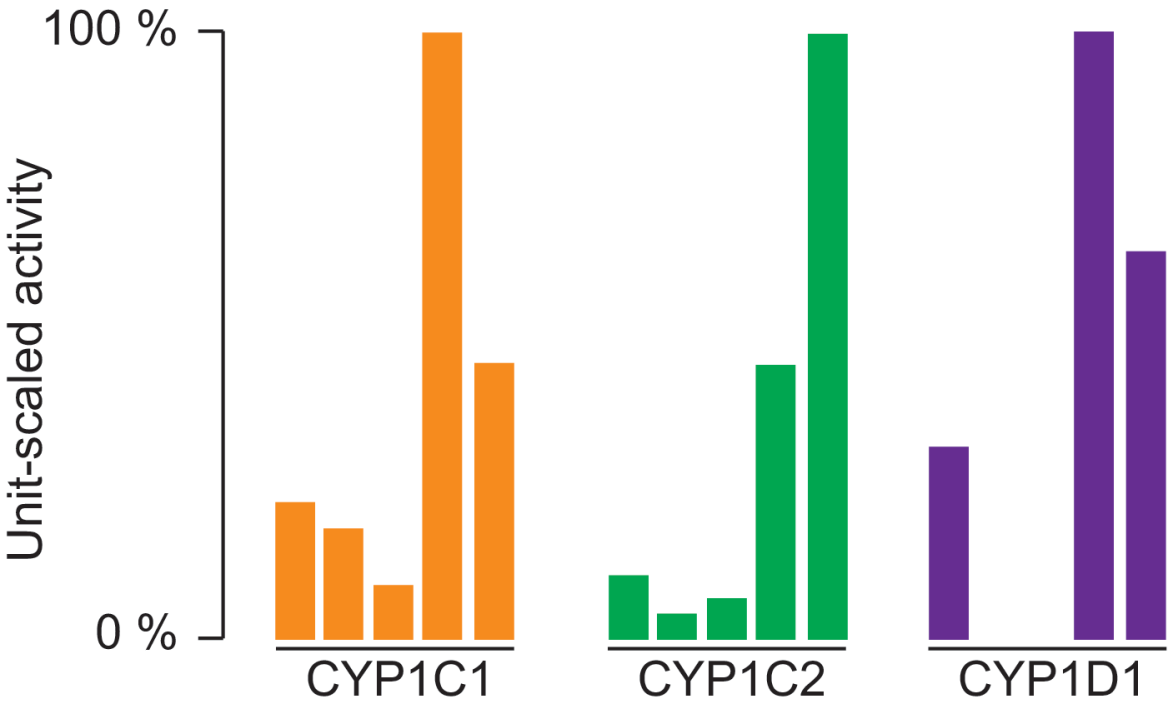

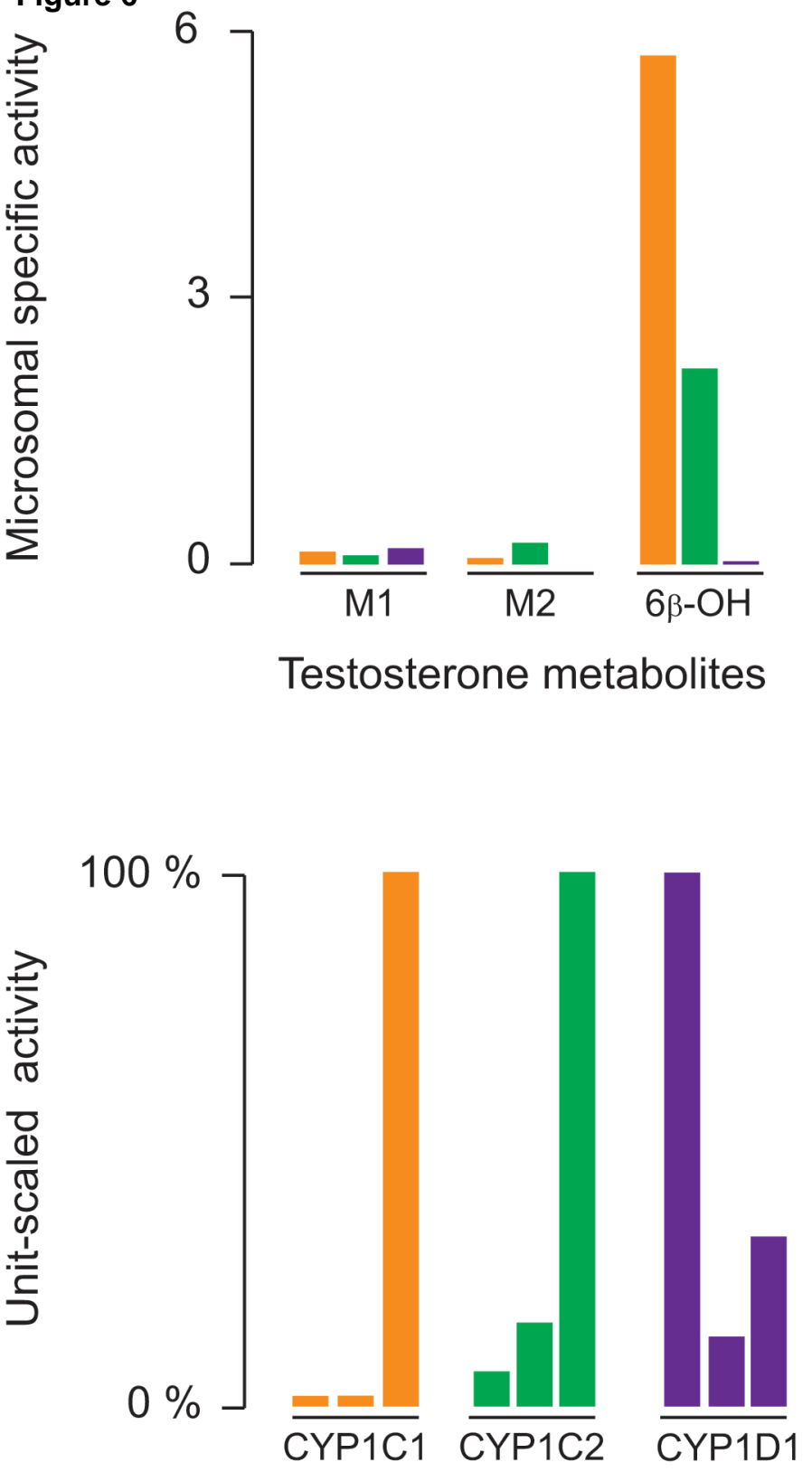
CYP1A

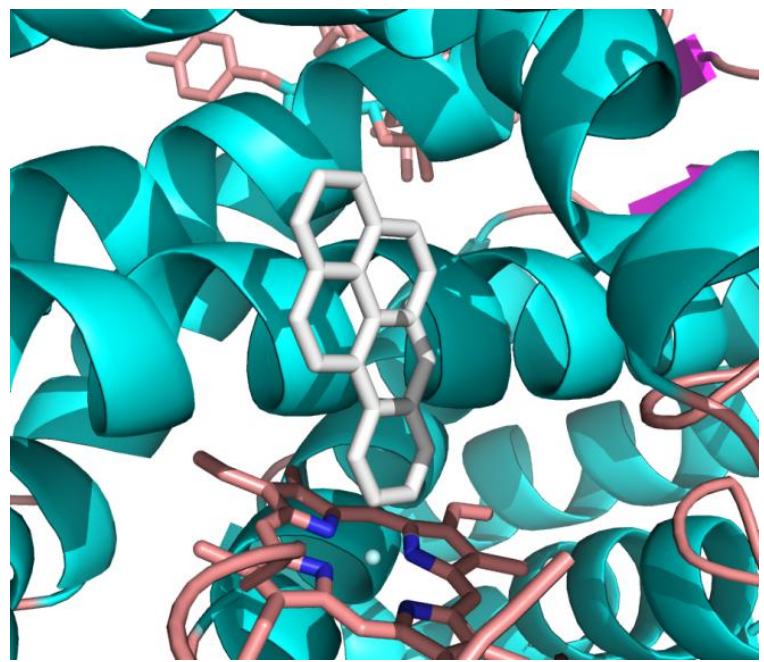

CYP1C1

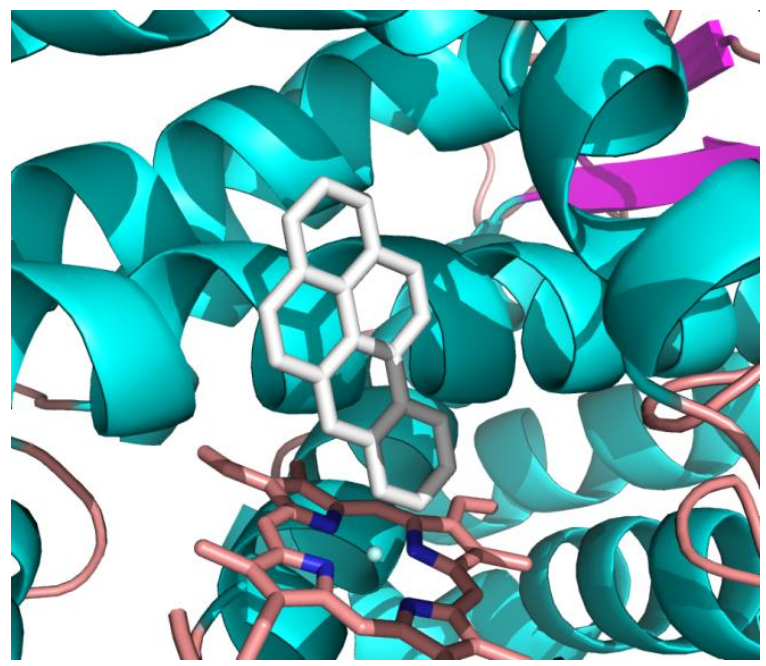

CYP1B1

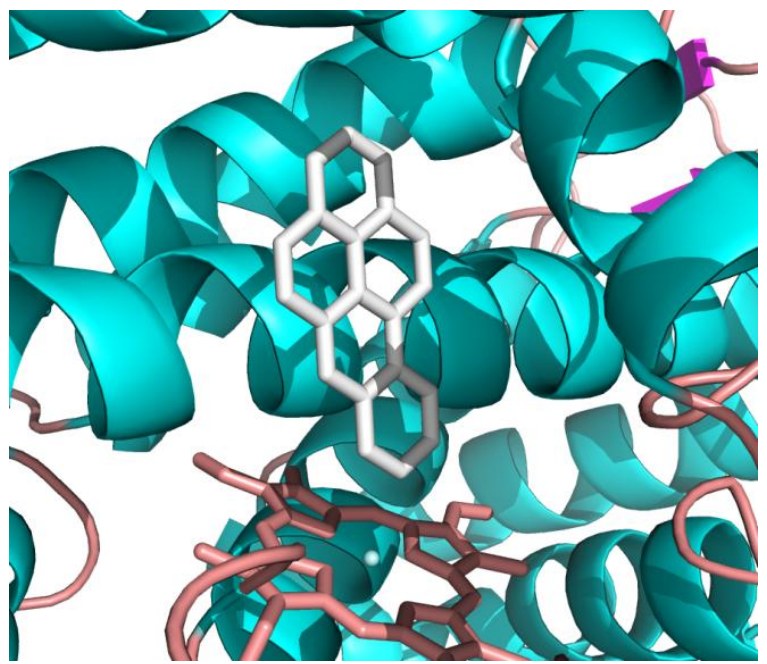

CYP1C2

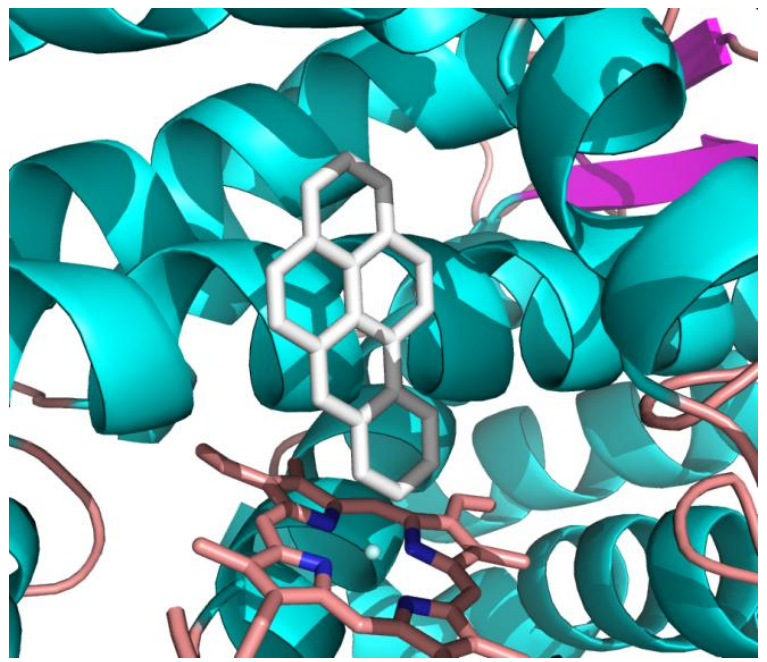

CYP1D1

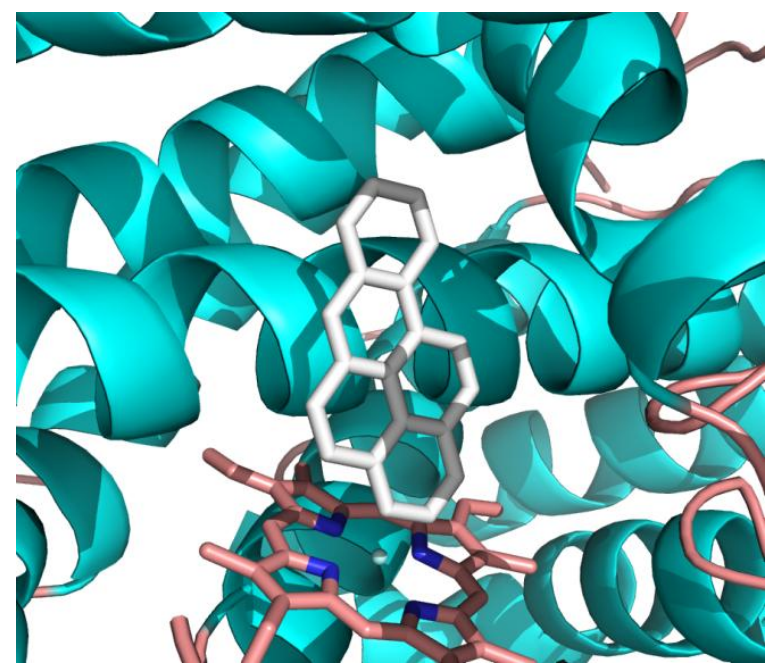


CYP1A

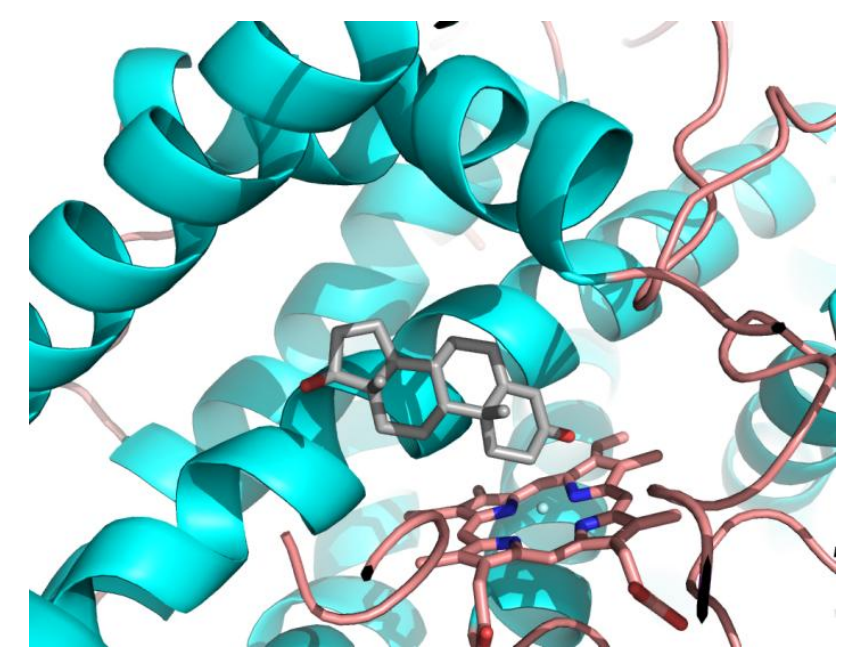

CYP1C1

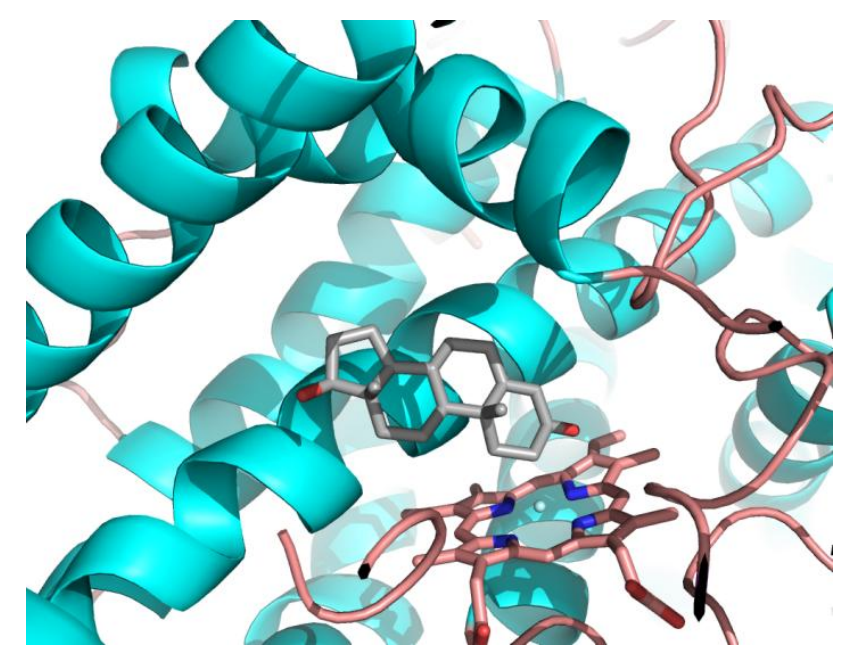

CYP1B1

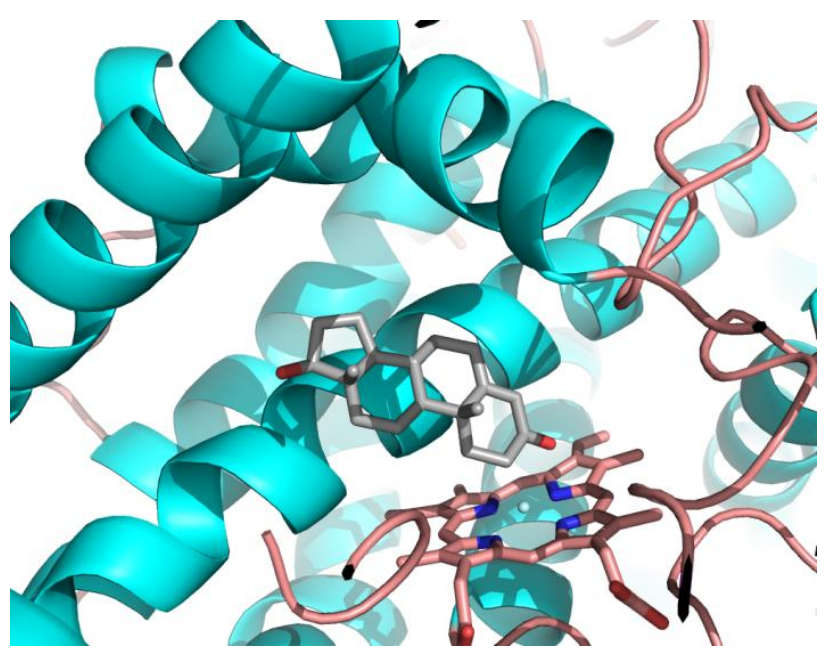

CYP1C2

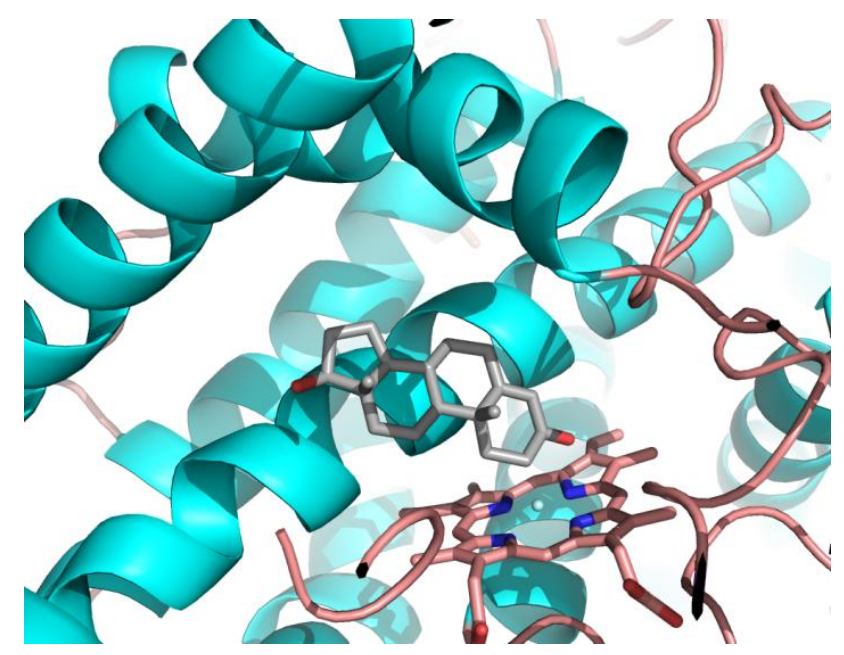

CYP1D1

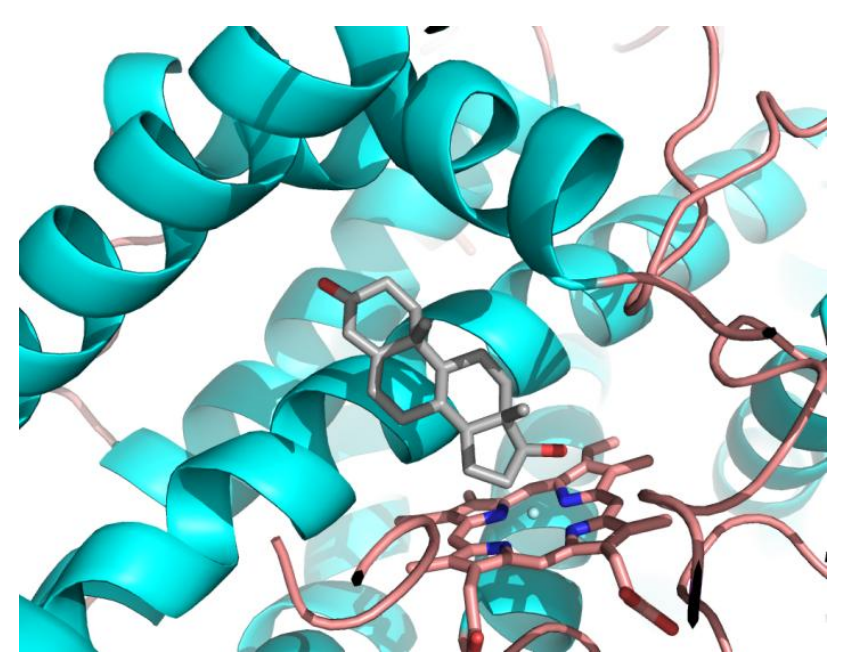

